\title{
Minimizing $\mathrm{Net}^{\mathrm{CO}_{2}}$ Emissions by Oxidative Co-Pyrolysis of Coal / Biomass Blends
}

Final Technical Report

Principal authors: $\quad$ Todd Lang, Brown University

Robert Hurt, Brown University

Report Issue Date: $\quad$ December 23, 2001

DOE Award Number: $\quad$ DE-FG26-OONT40827

Submitting Organization: Brown University (R. Hurt)

Division of Engineering, Box D

Providence, RI 02912 


\section{Disclaimer}

This report was prepared as an account of work sponsored by an agency of the United States Government. Neither the United States Government nor any agency thereof, nor any of their employees, makes any warranty, express of implied, or assumes any legal liability or responsibility for the accuracy, completeness, or usefulness of any information, apparatus, product, or process disclosed, or represents that its use would not infringe privately owned rights. Reference herein to any specific commercial product, process, or service by trade name, trademark, manufacturer, or otherwise does not necessarily constitute or imply its endorsement, recommendation, or favoring by the United States Government or any agency thereof. The views and opinions of authors expressed herein do not necessarily state or reflect those of the United States Government or any agency thereof. 


\begin{abstract}
This study presents a set of thermodynamic calculations on the optimal mode of solid fuel utilization considering a wide range of fuel types and processing technologies. The technologies include stand-alone combustion, biomass/coal cofiring, oxidative pyrolysis, and straight carbonization with no energy recovery but with elemental carbon storage. The results show that the thermodynamically optimal way to process solid fuels depends strongly on the specific fuels and technologies available, the local demand for heat or for electricity, and the local baseline energyproduction method. Burning renewable fuels reduces anthropogenic $\mathrm{CO}_{2}$ emissions as widely recognized. In certain cases, however, other processing methods are equally or more effective, including the simple carbonization or oxidative pyrolysis of biomass fuels.
\end{abstract}


TABLE OF CONTENTS

EXECUTIVE SUMMARY .............................................................................. 5

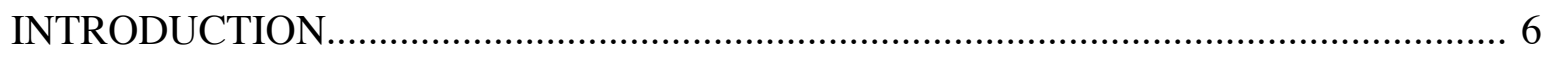

OBJECTIVE

APPROACH AND RESULTS …………………….............................................. 8

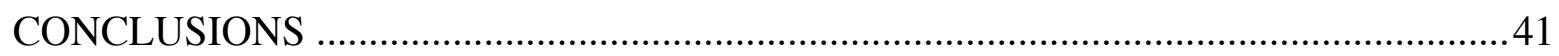

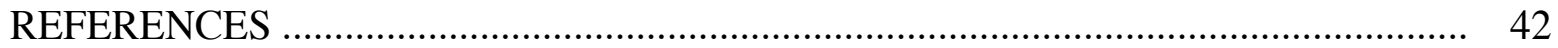




\section{EXECUTIVE SUMMARY}

This study presents a set of thermodynamic calculations on the optimal mode of solid fuel utilization, considering a wide range of fuel types and processing technologies. The technologies include stand-alone combustion, biomass/coal cofiring, oxidative pyrolysis, and straight carbonization with no energy recovery but with elemental carbon storage. The results show that the thermodynamically optimal way to process solid fuels depends strongly on the specific fuels and technologies available, the local demand for heat or for electricity, and the local baseline energyproduction method. Burning renewable fuels reduces anthropogenic $\mathrm{CO}_{2}$ emissions as widely recognized. In certain cases, however, other processing methods are equally or more effective, including the simple carbonization or oxidative pyrolysis of biomass fuels.

Specifically, the thermodynamic analyses carried out here lead to the following conclusions:

1. Of all practical solid fuels, elemental carbon (char) produces the largest amount of carbon dioxide per unit heating value, and is the worst fuel for global warming concerns. As a result, partial combustion processes, or "oxypyrolysis" process, that leave part or all of the char unburned always produce lower $\mathrm{CO}_{2}$ emissions per unit heating value than conventional combustion.

2. Carbonization of biomass and other fast-decaying waste fuels can produce a significant reduction in net $\mathrm{CO} 2$ emissions evne without energy recovery . Waste fuel carbonization and elemental carbon storage may be the most viable global warming abatement technology in some locations in the developing world, and in some local settings in the developed world where natural gas is fired as a baseline fuel (see below).

3. The relative merits of combustion, oxidative pyrolysis, and carbonization depend strongly on the fuel type, the local heating/electricity needs, and the baseline fossil fuel in the region of interest. Specifically:

(a) in an environment with coal-based power generation, biomass cofiring is the most attractive practical utilization scheme for global warming abatement. Biomass carbonization offers about $50 \%$ of the benefit and has the added complexity of carbon storage. Oxidative pyrolysis is the most effective thermodynamically (as in all cases) but the additional $\mathrm{CO}_{2}$ reduction is only about $10 \%$ and would like not justify the additional complexity associated with power station retrofit and the storage of high-carbon waste streams.

(b) in an environment with natural-gas based power generation, cofiring is not possible and biomass fuels would need to be burned in dedicated units. These units have lower efficiencies and further are producing power that displaces methane, which itself has a lower emissions index than coal. As a result, the carbonization of biomass in this scenario offers almost twice the $\mathrm{CO}_{2}$ offset as conventional combustion and is slightly higher than gasification.

In general, biomass carbonization or oxypyrolysis with carbon storage may be an attractive option for global warming abatement at local sites where there is (1) little need for steam heat, and (2) there is no possibility for electricity generation, or where electricity is already generated by natural gas. For these particular cases the thermodynamic analyses carried out here should be extended to a detailed engineering and commercial analysis that considers optimal charring technologies, equipment selection, process economics, issues of societal acceptance, and the role of this strategy in the overall world effort at global warming abatement. 


\section{INTRODUCTION}

Recent predictions on the effects of global warming have spurred interest in recognizing and managing the factors that influence it. It is known that the concentration of carbon dioxide in the earth's atmosphere is increasing. Infrared-active carbon dioxide absorbs radiation emitted by the earth. A consensus is developing to support the claim that $\mathrm{CO}_{2}$ emissions, among other gases such as $\mathrm{CH}_{4}$ and $\mathrm{NO}_{2}$, contribute to global warming by trapping radiative heat in the atmosphere. The gradually increasing tropospheric concentrations of these gases, trapping the radiative heat, is known as the greenhouse effect.

In 1995 the Intergovernmental Panel on Climate Change (IPCC) released its Group 1 report on global climate changes, in which $\mathrm{CO}_{2}$ emissions (or equivalents) are predicted to double by the next century [IPPC, 1996]. A prediction of the result of this atmospheric increase in greenhouse gas concentrations had been made years earlier that, as a best estimate, a $2{ }^{\circ} \mathrm{C}$ global temperature rise is expected by the year 2100 [National Research Council, 1979]. The IPCC concurred [Hallman and Steinberg, 1999]. Efforts and suggestions by the IPCC to combat the predicted temperature rise, however, were focused within the next forty years. Although meteorological variance has an acknowledged influence, there is compelling evidence that anthropological activity has spurred the most recent increase atmospheric $\mathrm{CO}_{2}$ concentrations. This evidence includes ice core sampling [IPCC, 1996] and monthly atmospheric sampling atop Mauna Lau in Hawaii [Keeling and Whorf, 1995]. The rapid concentration increase coincides with the commencement of the Industrial Age and, thus, thought to be largely due to the burning of fossil fuels.

The approaches to combat global warming are numerous. Many of the approaches to the reduction of carbon dioxide emissions to the atmosphere involve the capture of post-process $\mathrm{CO}_{2}$ for storage or use. Storage of carbon dioxide first requires the separation and capture of $\mathrm{CO}_{2}$ from the burning fuel waste stream. Methods to do so include chemical and physical adsorption, low-temperature distillation, and gas-separation membranes. Separation from flue gases in fossil fueled power plants, however, generally suffers from the fact that the $\mathrm{CO}_{2}$ concentrations are small compared with nitrogen and water vapor. Once captured, storage of the carbon dioxide has been proposed using sequestration in the deep ocean, terrestrial ecosystems, and geologic formations such as defunct coal or mineral mines. These proposed technologies have been extensively reviewed in both the scientific community [American Chemical Society, 2000 and Johansson, et al., 1996] and in the government sector [Office of Science, et al., 1999]. Another approach involves separating the fuelbound carbon as carbon dioxide before combustion, through catalytic oxidation with hightemperature steam [Mori, et al., 1993]. Use of the carbon dioxide waste gases, as opposed to sequestration, has also been advocated. Steinberg has proposed a "Carnol" process [Steinberg, 1997 and Steinberg, 1996] for waste $\mathrm{CO}_{2}$ use, which catalytically reacts the $\mathrm{CO}_{2}$ with $\mathrm{H}_{2}$ from the thermal decomposition of methane to produce methanol and solid carbon. Storage of carbon in its stable, solid from is assumed to be easier than storage of carbon dioxide as a reactive gas or lowtemperature liquid.

As an alternative approach to reducing $\mathrm{CO}_{2}$ emissions, several processes have been suggested for reducing $\mathrm{CO}_{2}$ production. Several suggestions have been for decreased reliance on fossil fuel combustion, through increased implementation of non-combustion energy sources such as hydroelectric power, wind turbines, solar energy capture, and nuclear power. Others suggest simple modifications to our current practices such as conservation and the development and use of higher- 
efficiency equipment. Manipulation of the current carbon cycle through reforestation has also been considered [Yokoyama, 1997].

Still several other methods have been proposed that are designed to further fossil fuel technology. For example, Bilger examined the use of oxygen rather than air as the oxidant for combustion, eliminating many of the dilutants that contaminate the carbon dioxide and water vapor exhaust [Bilger, 1999a]. Another intriguing possibility is the decarbonization of fossil fuels [Steinberg, 1999b]. The model fuel for this process is methane, which would decompose into fuel hydrogen and solid carbon, though the extension of this technology to solid fuels is equally encouraging. In particular, the carbonization of biomass has been considered by Bilger [Bilger, 1999b], who also has mentioned, though in little detail, the oxidation of the resulting volatile gases from carbonization for process energy [Bilger, 1999c], known as oxidative pyrolysis, or oxypyrolysis.

Fuel selection alone has a large influence on $\mathrm{CO}_{2}$ emissions. The amount of carbon dioxide produced per unit of thermal energy produced is known to vary significantly across the range of practical fuels, including fossil fuels, biomass, and waste fuels [Tillman, 1991 and Klass, 1998]. The energy-specific carbon emissions, the ratio of the amount of carbon (or carbon dioxide) to the energy released, provide insight into the potential global warming effects. Natural gas combustion has the lowest specific $\mathrm{CO}_{2}$ emission rate of all fossil fuels at $\sim 14 \mathrm{~g} \mathrm{C} / \mathrm{MJ}$, compared to $\sim 19 \mathrm{~g}$ $\mathrm{C} / \mathrm{MJ}$ for oil and $\sim 25 \mathrm{~g} \mathrm{C} / \mathrm{MJ}$ for coal. As a renewable resource, biomass offers the attraction of zero net carbon emissions, since it is neutral in the natural carbon cycle.

Thermal processes other than combustion will alter the specific emissions. As qualitative reasoning would suggest, global warming, will be affected to varying degrees depending on the choice of fuel and fuel process in question:

1. combustion, where the fuel is completely oxidized for energy extraction,

2. oxidative pyrolysis, where only the volatile matter is oxidized by combustion for energy extraction, while a solid char remains, or

3. carbonization, where a solid char is formed via pyrolysis, but no energy is extracted in the process.

Measures such as the specific carbon emissions are necessary to quantify the effects of fuel technologies on global warming. However, comparison of these values has so far been limited to fossil fuel combustion. Consideration of fuels other than fossil fuels and technologies other than combustion will have different impacts. Therefore, incorporation of these ideas into a single, cohesive study is necessary.

Of course, selection of any fuel raises many practical issues, including: drying processes, $\mathrm{NO}_{\mathrm{x}}$ and $\mathrm{SO}_{\mathrm{x}}$ emissions, heavy metals contamination, fouling and slagging, and ash utilization. These phenomena are known to vary widely with fuel type and should be considered in detail before implementation of any new process. 


\section{OBJECTIVE}

The goal of this project was to carry out a large set of systematic thermodynamic calculations to identify the most promising solid fuel technology options to minimize overall $\mathrm{CO}_{2}$ emissions. In general, the net energy-specific $\mathrm{CO}_{2}$ emission is found to be the result of a complex interplay among three factors:

1. fuel selection (including coals, petroleum, natural gas, biomass fuels, and waste fuels),

2. technology selection (including combustion, oxidative pyrolysis, and carbonization),

3. existing (baseline) regional fossil energy technology (including bituminous coal combustion and natural gas combustion) that would be displaced by any proposed alternate fuel or technology.

Simultaneous consideration of these three factors for a wide range of fuel types leads to a large, 3-dimensional matrix of options for which careful and systematic calculations are needed.

\section{APPROACH AND RESULTS}

\section{Direct Carbon Emissions (DCE)}

In an effort to address the possible threat of global warming, an assessment of various methods for the conversion of several fuels to energy was performed. First, an index was created to account for energy specific carbon dioxide emissions. The comparative index chosen to evaluate the scenarios is the ratio of carbon dioxide production to the energy evolved:

$$
D C E \equiv \frac{n_{\mathrm{CO}_{2}}}{\Delta h}
$$

where DCE is the "(D)irect (C)arbon (E)missions", $n_{\mathrm{CO} 2}$ is the number of moles of carbon dioxide produced per unit mass of fuel, and $\Delta \mathrm{h}$ is a mass-specific energy liberation. This index depends on the moisture content in the fuel, and therefore was considered on both a dry and wet bases. To calculate the DCE, both a fuel and a process must be declared.

This study considers three distinct processes: combustion, oxidative pyrolysis, and carbonization. Combustion is associated with energy extraction from the total fuel. During oxidative pyrolysis, or oxypyrolysis, energy is only extracted from the volatile portion of a fuel. As there is no energy extraction associated with carbonization, the DCE measure is not applied to this process.

\section{DCE for Combustion}

Chemically, combustion is the complete oxidation of a fuel, although there are different considerations that depend on the phase of the fuel considered. For example, combustion of liquid and vapor fuels produces only gaseous products, while the combustion of solid fuels produces ash 
as well. As a consequence, the equipment used for solid fuel combustion differs drastically from that for gaseous combustion, as does the practical measure of efficiency for both.

\section{Calculation of Combustion DCE}

Thermodynamically, however, the specific energy extracted by combustion of any fuel, no matter the phase, is simply the "heating value" of the fuel. The higher heating value (HHV) for a fuel includes the full energy content as defined by bringing all products of combustion to $25^{\circ} \mathrm{C}$ ( 298 $\mathrm{K}$ ), while the lower heating value (LHV) accounts for the energy lost to the vaporization of product water. For this study, LHV is used throughout, since it more accurately reflects the fuel's energy content in the absence of additional, separate calculations of stack losses. The DCE for combustion, then, can be expressed as:

$$
D C E_{\text {combustion }}=\frac{n_{\mathrm{CO}_{2}}}{L H V} \text {. }
$$

where the LHV assumes the complete combustion of fuel to $\mathrm{H}_{2} \mathrm{O}$ vapor and $\mathrm{CO}_{2}$. Necessarily, then, all of the carbon present in the fuel is converted to carbon dioxide, so the number of moles of $\mathrm{CO}_{2}$ produced can be calculated as:

$$
n_{\mathrm{CO}_{2}}=\frac{w t \% C / 100}{M W_{C}},
$$

where $\mathrm{wt} \%-\mathrm{C}$ is measured on a dry fuel basis.

\section{Fuel Properties}

Values for the weight percentage of carbon in the dry fuel are taken from the given fuel's ultimate analysis (Table 1a), obtained from various sources. Values for coal were taken from the Penn State Coal Bank, while values for biomass and other fuel sources were obtained from handbooks or combustion literature, as reported in Table 1. Values for the proximate analysis (Table 1b) of methane and petroleum assume that the material can be "cracked" to form a solid containing $100 \%$

of the carbon, while the hydrogen composes the volatile matter. 
Table 1: (a) Ultimate analysis (dry basis), and (b) proximate analysis and heating values (dry basis) for various fuel sources.

(a)

(b)

\begin{tabular}{|c|c|c|c|c|c|c|}
\hline & & wt\% & wt \% & \multirow[t]{2}{*}{$\begin{array}{l}\text { wt\% } \\
\mathbf{N}\end{array}$} & wt\% & wt\% \\
\hline fuel & wt\% C & $\underset{5607}{\mathbf{H}}$ & $\begin{array}{l}\mathbf{O} \\
0.67\end{array}$ & & $\mathbf{S}$ & ash \\
\hline & & $4.56 \%$ & $8.16 \%$ & $1.11 \%$ & $4.52 \%$ & \\
\hline coal-hvAb & $74.21 \%$ & $5.10 \%$ & $6.03 \%$ & $1.35 \%$ & $3.87 \%$ & $9.44 \%$ \\
\hline coal-lvb $^{c}$ & $85.74 \%$ & $4.67 \%$ & $3.16 \%$ & $1.09 \%$ & $0.74 \%$ & $4.60 \%$ \\
\hline coal-subB $^{\mathrm{d}}$ & $70.73 \%$ & $4.85 \%$ & $16.8 \%$ & $0.84 \%$ & $0.41 \%$ & $6.37 \%$ \\
\hline coal-lig $^{\mathrm{e}}$ & $66.15 \%$ & $4.03 \%$ & $18.6 \%$ & $0.90 \%$ & $0.74 \%$ & $9.56 \%$ \\
\hline brown coal ${ }^{\mathrm{f}}$ & $64.98 \%$ & $5.00 \%$ & $24.0 \%$ & - & $0.25 \%$ & $5.75 \%$ \\
\hline peat ${ }^{\mathrm{g}}$ & $52.80 \%$ & $5.45 \%$ & $31.2 \%$ & $2.54 \%$ & $0.23 \%$ & $7.74 \%$ \\
\hline biomass-woody ${ }^{\mathrm{h}}$ & $45.68 \%$ & $8.24 \%$ & $45.4 \%$ & $0.00 \%$ & $0.00 \%$ & $0.70 \%$ \\
\hline herbaceous ${ }^{i}$ & $45.15 \%$ & $5.15 \%$ & $42.9 \%$ & $0.75 \%$ & $0.14 \%$ & $5.87 \%$ \\
\hline methane $\mathrm{j}^{\mathrm{j}}$ & $74.87 \%$ & $25.1 \%$ & $0.00 \%$ & $0.00 \%$ & $0.00 \%$ & $0.00 \%$ \\
\hline$(\text { crude })^{\mathrm{k}}$ & $86.06 \%$ & $13.9 \%$ & $0.00 \%$ & $0.00 \%$ & $0.06 \%$ & $0.00 \%$ \\
\hline waste tires ${ }^{1}$ & $83.80 \%$ & $7.60 \%$ & $3.10 \%$ & $0.40 \%$ & $1.40 \%$ & $3.70 \%$ \\
\hline carbon $_{(\mathrm{gr})}{ }^{\mathrm{j}}$ & $100.0 \%$ & $0.00 \%$ & $0.00 \%$ & $0.00 \%$ & $0.00 \%$ & $0.00 \%$ \\
\hline fuel & $\begin{array}{c}\text { wt\% } \\
\text { moisture }\end{array}$ & $\begin{array}{l}\text { wt\% } \\
\text { ash }\end{array}$ & \multicolumn{2}{|c|}{ wt $\%$ vi $\%$} & $\%$ & $\mathbf{I V}, \mathrm{Btu} / \mathrm{lb}$ \\
\hline coal-hvCb & $10.43 \%$ & $14.47 \%$ & $34.16 \%$ & 40.9 & & 11,880 \\
\hline coal-hvAb & $2.40 \%$ & $10.00 \%$ & $35.16 \%$ & 52.4 & & 13,614 \\
\hline coal-lvb & $1.01 \%$ & $4.55 \%$ & $18.13 \%$ & 76.3 & & 15,006 \\
\hline coal-subB & $24.68 \%$ & $4.80 \%$ & $33.46 \%$ & 37.1 & & 12,330 \\
\hline coal-ligA & $33.38 \%$ & $6.37 \%$ & $37.36 \%$ & 22.9 & & 11,062 \\
\hline brown coal & $60.00 \%$ & $2.30 \%$ & $20.60 \%$ & 17.1 & & 11,150 \\
\hline peat & $33.38 \%$ & $6.37 \%$ & $37.36 \%$ & 22.9 & & 8,936 \\
\hline $\begin{array}{l}\text { biomass-woody } \\
\text { biomass- }\end{array}$ & $19.30 \%$ & $0.70 \%$ & $63.10 \%$ & 16.9 & & 8,485 \\
\hline herbaceous & $12.64 \%$ & $5.13 \%$ & $\begin{array}{l}66.00 \% \\
25.13 \%\end{array}$ & $\begin{array}{l}16.2 \\
74.9\end{array}$ & & 7,582 \\
\hline methane & $0.00 \%$ & $0.00 \%$ & $*$ & $*$ & & 23,861 \\
\hline $\begin{array}{l}\text { petroleum } \\
\text { (crude) }\end{array}$ & $0.00 \%$ & $0.00 \%$ & $\begin{array}{c}13.94 \% \\
*\end{array}$ & 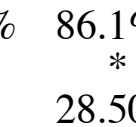 & & 19,505 \\
\hline waste tires & $0.50 \%$ & $3.70 \%$ & $67.30 \%$ & $\begin{array}{r}\% \\
100 .(\end{array}$ & & 15,667 \\
\hline carbon $_{(\mathrm{gr})}$ & $0.00 \%$ & $0.00 \%$ & $0.00 \%$ & $\%$ & & 14,087 \\
\hline $\begin{array}{l}\text { ssuming } 100 \% \text { cracked. } \\
\text { partment of Energy Coa } \\
\text { partment of Energy Coa } \\
\text { partment of Energy Coa } \\
\text { partment of Energy Coa } \\
\text { partment of Energy Coa }\end{array}$ & $\begin{array}{l}\text { nk at Penn State } \\
\text { nk at Penn State } \\
\text { nk at Penn State } \\
\text { nk at Penn State } \\
\text { nk at Penn State } \\
\text { erman brown co } \\
\text { peat, } 84.0 \mathrm{wt} \% \\
\text { ini, L., Fuel } 75 \\
\text { güdenler, A., an } \\
\text { ineering Therm } \\
\text { Eds.), Essential } \\
\text { rk, 1991. } \\
\text { K., and Sang, D }\end{array}$ & $\begin{array}{l}\text { "DECS-series } \\
\text { "DECS-series } \\
\text { "DECS-series } \\
\text { "DECS-series } \\
\text { "DECS-series } \\
\text { al). } \\
\text { moisture). } \\
\text { 5), p. 565-573, } \\
\text { i Sever, A., Ene } \\
\text { dynamics, 2nd } \\
\text { enoineering }\end{array}$ & $\begin{array}{l}\text { data printouts,", } \\
\text { d data printouts,", } \\
\text { d data printouts,', } \\
\text { d data printouts,', } \\
\text { data printouts,' } \\
\text { 1996. } \\
\text { Edgy \& Fuels } 1 \\
\text { idgpendix }\end{array}$ & $\begin{array}{l}\text {," DECS } \\
,, \text { DECS } \\
\text {,', DECS } \\
\text {,', DEC } \\
\text { DEC }\end{array}$ & $\begin{array}{l}\text { (Pittsbur } \\
\text { (Pocaho } \\
\text { (Dietz), } 1 \\
\text { (Beulah) }\end{array}$ & $\begin{array}{l}\text { ork, } 1989 . \\
.9 \text { (Pennsylvania }\end{array}$ \\
\hline
\end{tabular}




\section{Fuel Approximations}

For the denominator of the expression for DCE, calculation of the LHV from the HHV is necessary for each fuel. Here, an approximation of the fuel as a $\mathrm{CH}_{x} \mathrm{O}_{y}$ compound is made. This approximation is made by re-normalizing the $\mathrm{wt} \%-\mathrm{C}$, wt $\%-\mathrm{H}$, and $\mathrm{wt} \%-\mathrm{O}$ from the ultimate analysis results to reflect only those three elements, then converting the weight proportions to molar proportions using each element's respective molecular weight, and assuming a basis of 1 mole of carbon for 1 mole of fuel (Table 2).

Using this approach, the approximate stoichiometric number of moles of hydrogen and of oxygen per mole of fuel, $x$ and $y$, respectively, are determined. Then the balanced equation for complete combustion can be written:

$$
\mathrm{CH}_{x} \mathrm{O}_{y}+\left(1+\frac{x}{4}-\frac{y}{2}\right) \mathrm{O}_{2}-->\mathrm{CO}_{2}+\frac{x}{2} \mathrm{H}_{2} \mathrm{O} \text {. }
$$

Table 2: Approximations for various fuel sources as $\mathrm{CH}_{\mathrm{x}} \mathrm{O}_{\mathrm{y}}$ compounds, based on elemental compositions given in Table 1a.

$\begin{array}{lcccc}\text { fuel } & \text { mol } & \boldsymbol{x} \text { mol } & \boldsymbol{y} \text { mol } & \\ \text { coal-hvCb } & \mathbf{C} & \mathbf{H} & \mathbf{O} & \mathbf{M W}_{\text {fuel }}[\mathbf{g} / \mathbf{m o l}] \\ \text { coal-hvAb } & 1 & 0.830 & 0.094 & 14.34 \\ \text { coal-lvb } & 1 & 0.819 & 0.061 & 13.81 \\ \text { coal-subB } & 1 & 0.649 & 0.028 & 13.11 \\ \text { coal-ligA } & 1 & 0.817 & 0.178 & 15.69 \\ \text { brown coal } & 1 & 0.726 & 0.211 & 16.12 \\ \text { peat } & 1 & 0.917 & 0.277 & 17.37 \\ \text { biomass-pine } & 1 & 1.230 & 0.444 & 20.36 \\ \text { biomass-straw } & 1 & 2.150 & 0.746 & 26.11 \\ \text { methane } & 1 & 1.359 & 0.714 & 24.80 \\ \text { petroleum } & 1 & 4.000 & 0.000 & 16.04 \\ \text { (crude) } & 1 & 1.922 & 0.000 & 13.95 \\ \text { waste tires } & 1 & 1.081 & 0.028 & 13.54 \\ \text { carbon (g) } & 1 & 0.000 & 0.000 & 12.01\end{array}$

The approximate molecular weight of the fuel $\left(\mathrm{MW}_{\text {fuel }}\right)$ from Table 2 is necessary for calculating the LHV from the HHV [Wark, Jr., 1988]:

$$
L H V_{d r y}=H H V_{d r y}-\Delta h_{v a p, H_{2} O}^{o}\left(\frac{x}{2}\right) \frac{M W_{H_{2} O}}{M W_{\text {fuel }}}
$$

Where $x$ is the moles of hydrogen per mole of fuel, as indicated in Table 2, and the enthalpy of vaporization of water is given at standard temperature, $298 \mathrm{~K}$. When considering a wet fuel basis, an additional factor must be applied to the amount carbon dioxide produced:

$$
n_{\mathrm{CO}_{2 w e t}}=N_{\mathrm{CO}_{2 d r y}}\left(1-\frac{w t \% \mathrm{H}_{2} \mathrm{O}}{100}\right),
$$


where $\mathrm{wt} \%-\mathrm{H}_{2} \mathrm{O}$ is measured on a wet fuel basis. Additionally, the LHV of the fuel must include the energy required to vaporize the moisture content of the raw fuel:

$$
L H V_{w e t}=L H V_{d r y}\left(1-\frac{w t \% H_{2} O}{100}\right)-\Delta H_{v a p, H_{2} O}\left(\frac{w t \% H_{2} O}{100}\right)
$$

where the enthalpy of vaporization of water is $2.26[\mathrm{MJ} / \mathrm{kg}]$.

\section{DCE Values for Combustion}

The calculated value of the combustion DCE for each fuel on a dry basis and on a wet basis are presented in Figure 1. From this figure, it is apparent that there is significant variability of the direct carbon emissions of the fuels. Even considering solid fuels alone (all fuels shown with the exception of methane and petroleum), the values vary from approximately 2 to 2.5 [mol $\mathrm{CO}_{2} / \mathrm{MJ}_{\mathrm{LHV}}$, depending on the fuel and the moisture content.

Elemental carbon is the worst fuel for combustion, exhibiting the highest DCE of all fuels considered. This trend can be expected to persist no matter what solid fuel is proposed, with the exception of perhaps a brown coal or peat with very high moisture content. A general trend of DCE among the coals and peat is also apparent: it generally increases with decreasing coal rank, becoming noticeably worse for the geologically younger fuels, brown coal and peat. Combustion of waste tires looks particularly attractive, considering that they often reside in locations that consume valuable space (as in landfills), are unaesthetic (as on roadsides), or are potentially harmful (as in water sources), while the other fuels are found in relatively benign storage locations (underground or on topsoil).

One should bear in mind that the results for methane and petroleum are independent of the assumption made previously for the proximate analysis (Table 1), that $100 \%$ of the carbon in the hydrocarbon fuel can be theoretically cracked to form fixed carbon, with the remainder contributing to hydrogen-rich volatile matter. Further, the apparent superiority of methane (or, similarly, natural gas) as an environmentally friendly fuel for combustion appears greatest in these results, as consideration for the renewable nature of biomass sources have not been given. 


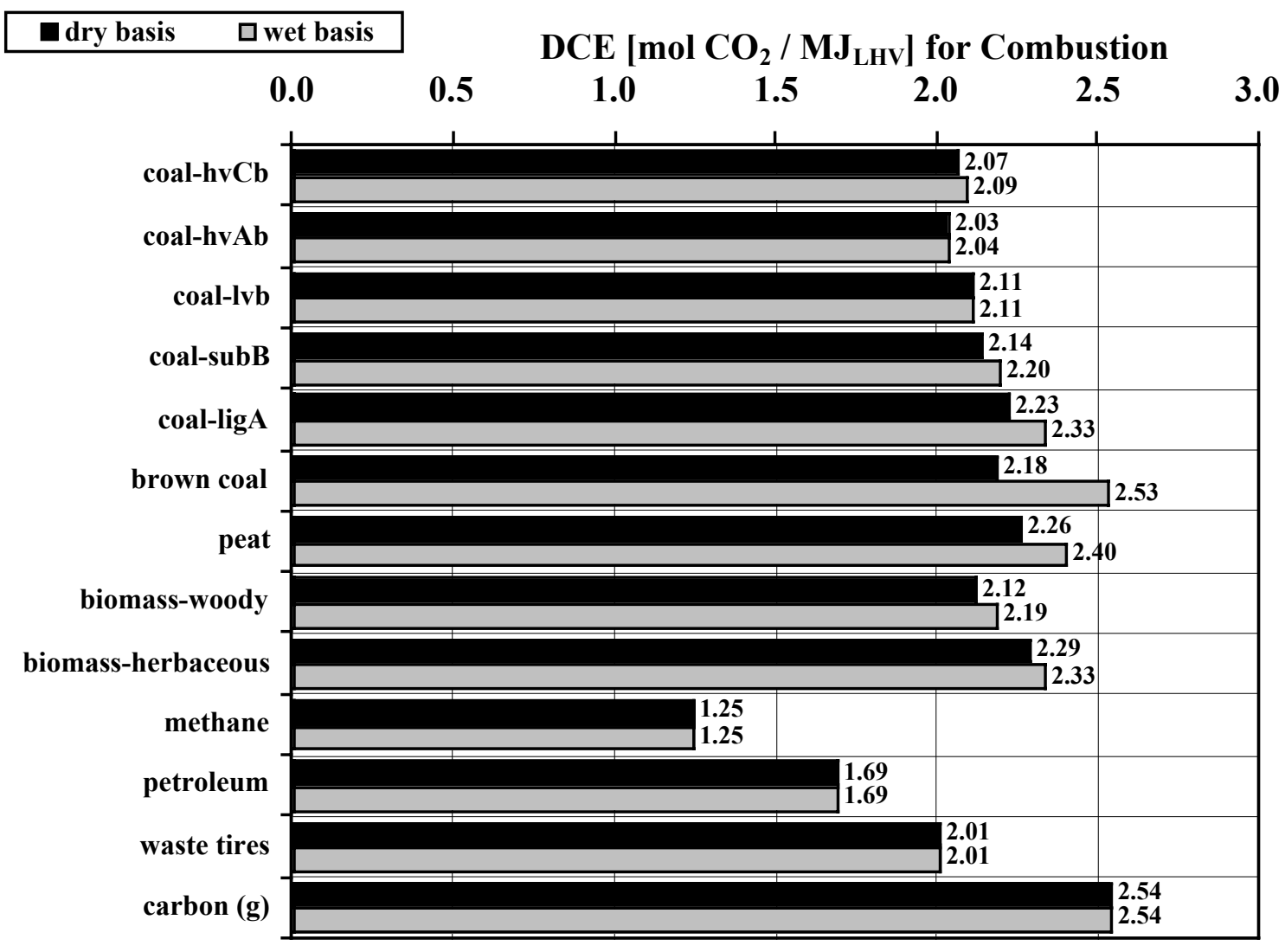

Figure 1: Direct Carbon Emissions (DCE) for combustion of various fuels.

\section{DCE for Oxypyrolysis}

The concept of the Direct Carbon Emissions can easily be extended to any thermochemical conversion process. The extension of the DCE definition allows a direct comparison of specific carbon dioxide emissions across various fuel-to-energy techniques. Oxidative pyrolysis, or oxypyrolysis, is one such alternative. Oxypyrolysis combines the ideas of two processes familiar in fuel conversion: pyrolysis and combustion. Oxypyrolysis mimics traditional pyrolysis in that the raw material thermally decomposes into volatile matter and char. It also involves combustion, though of the volatile matter alone. In this way, oxypyrolysis allows another technique by which energy can be extracted from the fuel. As only a fraction of the fuel is combusted, oxypyrolysis requires larger amounts of fuel than does complete combustion in order to meet a particular energy demand. However, oxypyrolysis was considered as an attractive alternative to combustion due to its inherent elimination of carbon oxidation.

\section{Calculation of Oxypyrolysis DCE}

The calculation of the $\mathrm{DCE}$ for this process, then, must account only for the heat and $\mathrm{CO}_{2}$ production that is associated with the combustion of the volatiles and not of fixed carbon: 


$$
D C E_{\text {oxypyrolysis }}=\frac{w t \% C-w t \% F C}{M W_{C}\left(100\left(L H V_{\text {fuel }}\right)-w t \% F C\left(L H V_{C}\right)\right)},
$$

where the weight percentages are on dry fuel bases and the lower heating values for the fuel and for carbon, $\mathrm{LHV}_{\text {fuel }}$ and $\mathrm{LHV}_{\mathrm{C}}$, respectively, are also given on dry bases. It is important to note that fixed carbon percentages are not, however, strictly determined by the fuel type. Rather, the fractionation of the hydrocarbon fuel into fixed carbon and volatile matter is dependent also on the method by which the decomposition occurs. Routinely, these values quoted from proximate analysis, characterized by ASTM standard D3172-89. However, it is also possible to determine these percentages based on chemical equilibrium, as will be discussed in detail later.

The numerator and denominator must be manipulated exactly as they were for combustion when considering the index on a wet fuel basis:

$$
D C E_{\text {oxypyrolysis, wet }}=\frac{(w t \% C-w t \% F C)}{M W_{C}\left(100 L H V_{\text {fuel }}-w t \% F C\left(L H V_{C}\right)\right)-100 \frac{\Delta H_{v a p, H_{2} O} w t \% H_{2} O}{100-w t \% H_{2} O}}
$$

\section{DCE Values for Oxypyrolysis (ASTM)}

Results using the same fuels as were introduced previously are represented in Figure 2. When considering the results displayed in the Figure 2, the elimination of carbon dioxide emissions by extracting energy by oxypyrolysis of methane, petroleum, or graphitic carbon is striking. It is essential to bear in mind, however, that the results for methane and petroleum are such because the assumption has been made here that the entire carbon content of these fuels can be converted to char. This "cracking" process, where all carbon in the material is converted to stable, solid elemental carbon as opposed to existing in volatile hydrocarbon species, may never realize the theoretical yield as suggested by the figure. Nevertheless, these two fuels illustrate the significant benefit of sequestering carbon in its elemental form and extracting energy only from the remaining hydrogen-rich fraction. The result for graphitic carbon is meaningless since it contains no volatile matter by our definition.

With those anomalies aside, there is a much larger variation in the DCE for the oxypyrolysis of the fuels than for their complete combustion, though the values are still typically about 2.5 [mol $\left.\mathrm{CO}_{2} / \mathrm{MJ}\right]$ or less. The renewable biomass fuels still have no advantage over the lower-rank solid fuels. The waste tires no longer seem a viable alternative to coal processing either. Interestingly, the DCE for higher-rank coals is quite favorable, especially for low volatile coals. The higher fixed carbon yield of these coals 


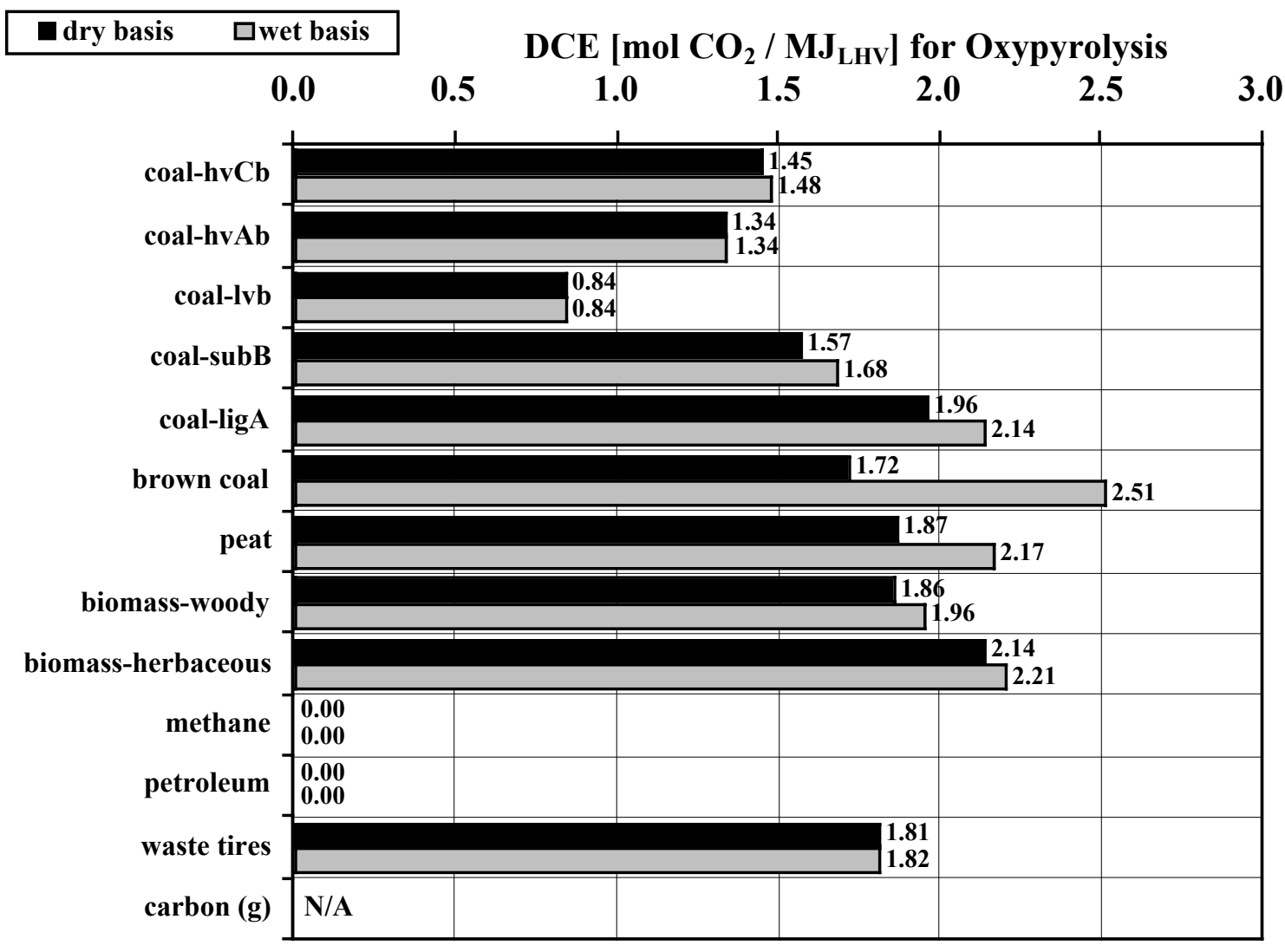

Figure 2: Direct carbon emissions (DCE) for oxidative pyrolysis of various fuels.

diminishes the amount of carbon released as carbon dioxide in the oxidation of the pyrolysis products, while the volatiles are necessarily richer in hydrogen. On the basis of the DCE alone, the oxidative pyrolysis of these coals is certainly the most attractive of the solid fuels. However, as at least 2/5 of the fuel mass is sequestered (over 3/4 in the case of the low-volatile bituminous coal) as elemental carbon in this process, the amount of coal that must be processed to meet a specific energy demand could become excessive. The trends in DCE for oxypyrolysis on a wet basis are similar to that on a dry basis, as was the case with combustion. One obvious exception is the oxypyrolysis of brown coal, which, on a wet basis, yields a DCE significantly higher than that of any other fuel. This effect is attributed to the abundance of moisture (about $60 \%$ by weight) in the fuel.

\section{Comparison of Combustion and Oxypyrolysis DCE}

A comparison of the DCE for combustion and for oxypyrolysis is of special interest (Figure 3). For all fuels, oxypyrolysis is better for global warming minimization than traditional combustion. Again, for methane and petroleum, oxypyrolysis appears much more favorable than combustion, but should be accompanied with the understanding that these yields assume $100 \%$ cracking of the materials. 


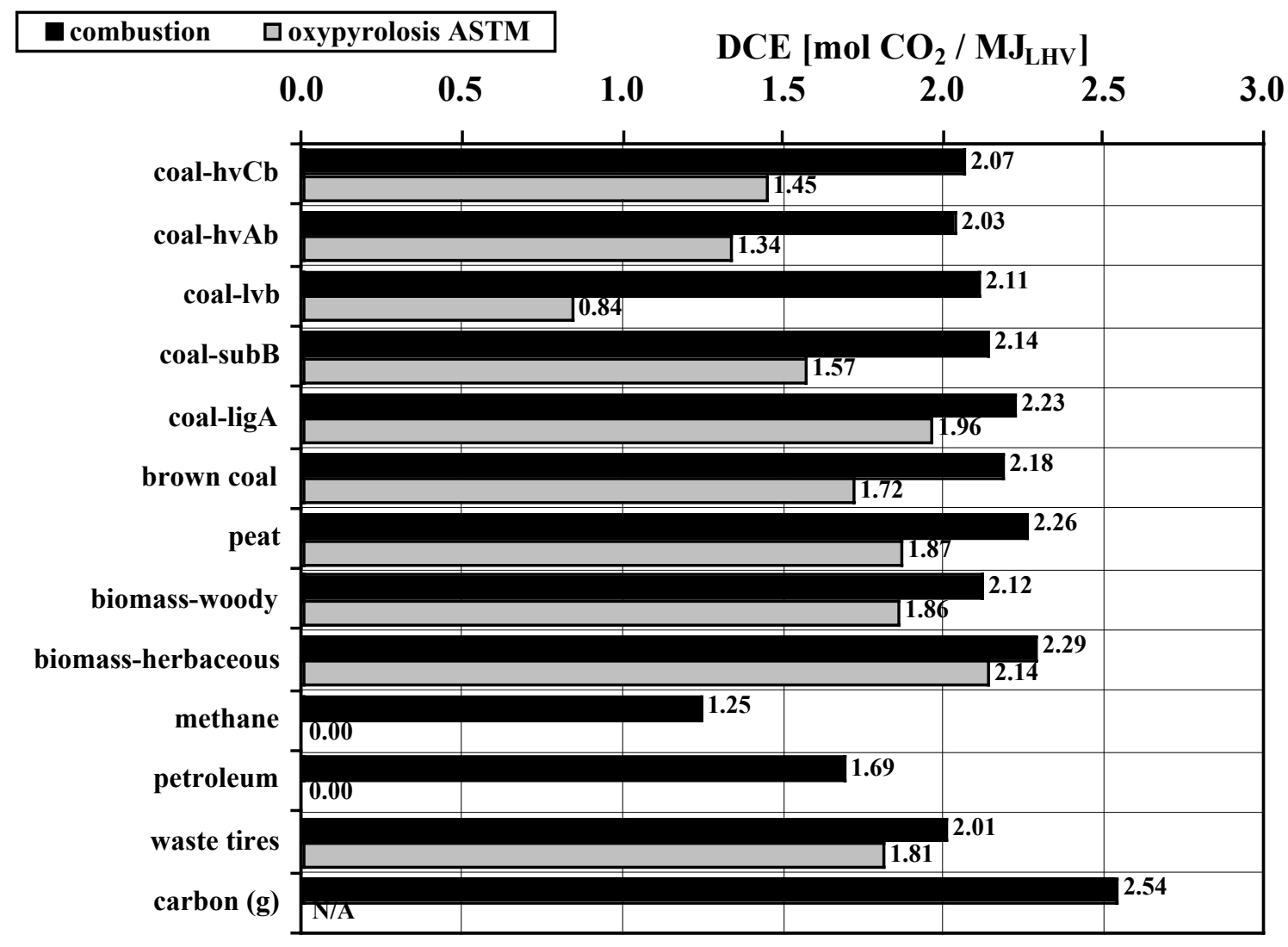

Figure 3: A comparison of Direct Carbon Emissions (DCE) for combustion and for oxidative pyrolysis for various potential fuels, on a dry fuel basis.

Considering the coals and peat, there are obvious reductions in DCE possible by carrying out oxypyrolysis over conventional combustion, the most remarkable being that of the low-volatile bituminous coal, which can theoretically realize a $60 \%$ reduction in DCE. On the basis of the other coals and peat, oxypyrolysis can offer significant, though slightly smaller, reductions in DCE. The reduction afforded by the renewable biomass sources and by waste tires is small but worth mention, on the order of $10 \%$.

The fact that oxypyrolysis reduces specific carbon dioxide emissions for all solid fuels is expected, since it avoids the combustion of elemental carbon (char) which was previously shown (Figure 1) to be the worst solid fuel. On a wet fuel basis (Figure 4), the trends are similar, with the exception of the severely detrimental effect of high moisture content as exhibited by the brown coal and peat.

\section{Equilibrium of $\mathrm{CH}_{x} \mathrm{O}_{y}$ Fuels}

As mentioned previously, the volatile matter and fixed carbon distribution of the pyrolysis products depends on the pyrolysis method being considered. When reporting direct carbon emissions values it is sensible to use the proximate analysis yields given by the ASTM standard. These ASTM values, however, are influenced by the pyrolysis 


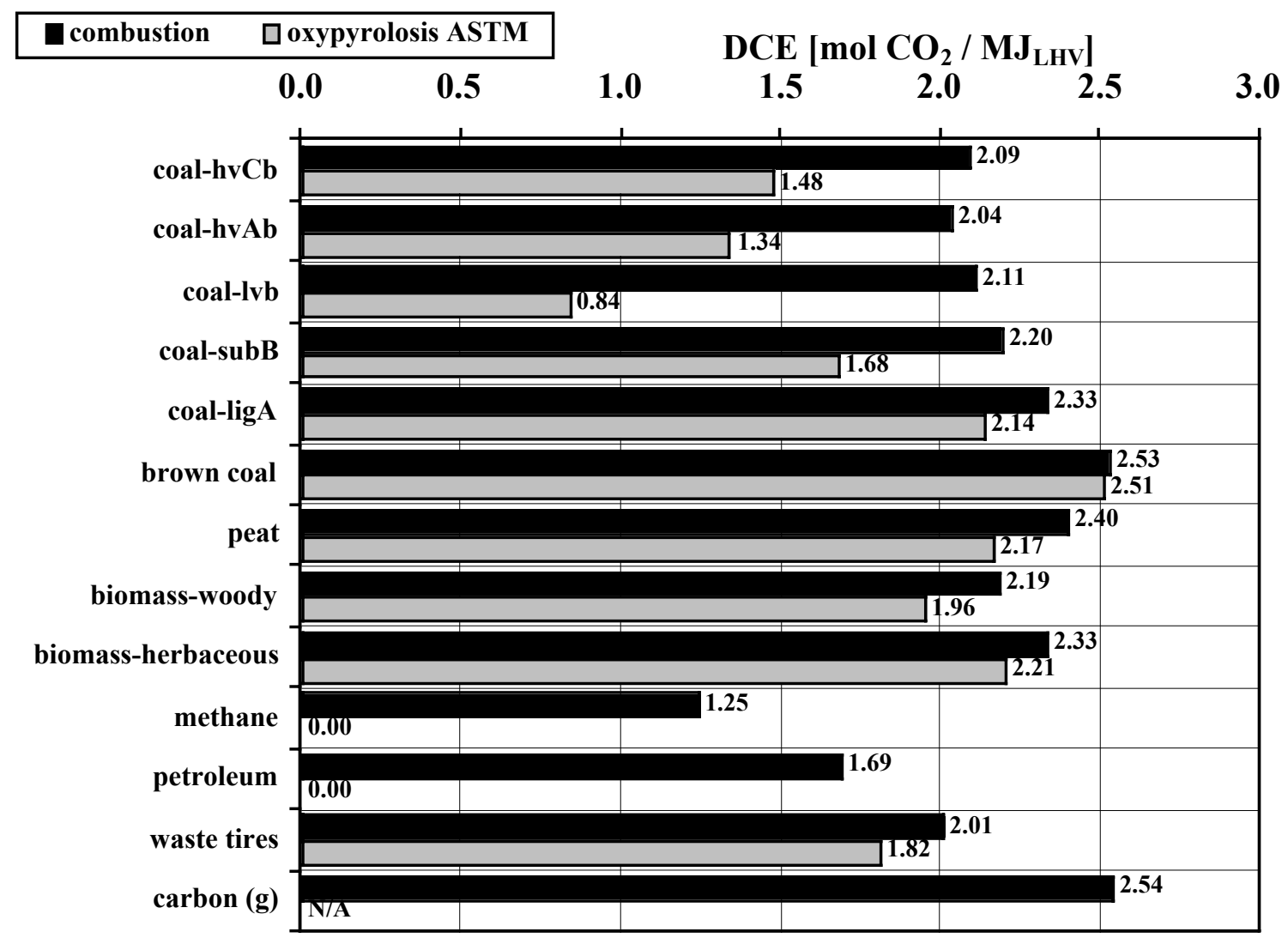

Figure 4: A comparison of Direct Carbon Emissions (DCE) for combustion and for oxidative pyrolysis for various potential fuels, on a wet fuel basis.

kinetics and by secondary reactions. For this reason, it is also insightful to use alternative methods for determining these yields. In particular, the thermodynamically-limiting volatile and char yields can be calculated from equilibrium considerations. To do so, a solid fuel may first be approximated as a $\mathrm{CH}_{x} \mathrm{O}_{y}$ compound, as detailed in Table 2. This approach then requires a selection of stable products of the system for which equilibrium will occur at any given temperature by minimization of the Gibb's free energy for all species. The equilibrium species considered here are $\mathrm{CO}, \mathrm{CO}_{2}$, $\mathrm{H}_{2} \mathrm{O}, \mathrm{CH}_{4}$, and $\mathrm{H}_{2}$. The distribution of these species, given as partial pressures, has been presented by Kyle [Kyle, 1999] in graphical form as a function of the atomic oxygen-to-hydrogen ratio $(y / x)$ and of the temperature of interest (Figure 5). Temperatures of $500 \mathrm{~K}$ and $1100 \mathrm{~K}$ have been considered for this investigation.

\section{Equilibrium of $\mathrm{CH}_{x}$ Fuels}

Although Figure 5 can be used to determine the equilibrium distributions for any $\mathrm{CH}_{x} \mathrm{O}_{y}$ compound, a different approach must be taken for oxygen-free $\mathrm{CH}_{x}$ compounds, including, in this case, $\mathrm{CH}_{4}$ and petroleum. For these fuels, equilibrium occurs between solid carbon, gaseous hydrogen, and gaseous methane: 

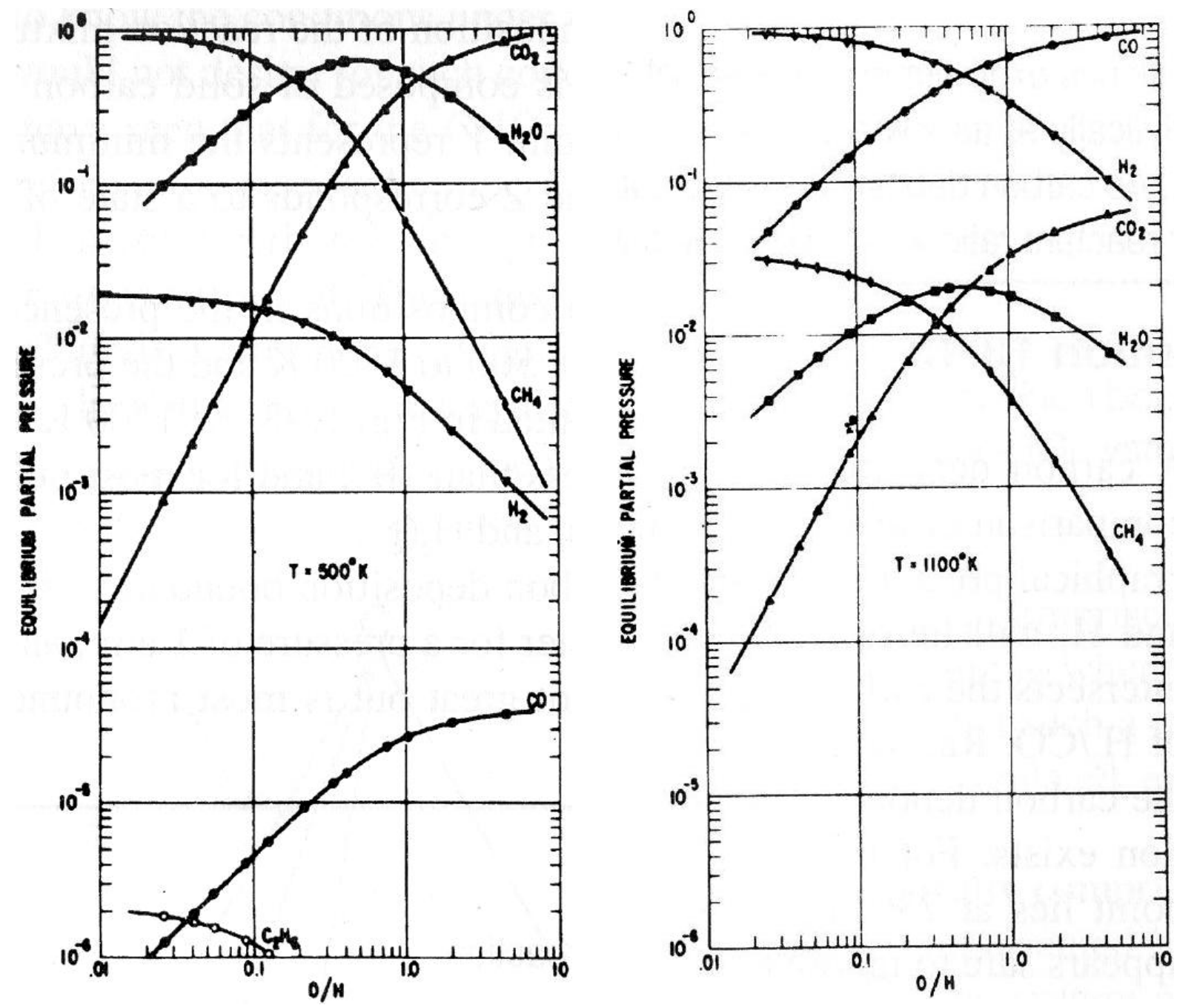

Figure 5: Partial pressures of gaseous species in equilibrium with carbon in the $\mathrm{CH}_{x} \mathrm{O}_{y}$ system at 1 [atm]. (From Kyle, 1999, p. 574).

$$
C_{(s)}+2 H_{2(g)}<=>C H_{4(g)},
$$

and an equilibrium constant can then be defined:

$$
K_{e q}(T)=\frac{P_{\mathrm{CH}_{4}}}{P_{\mathrm{H}_{2}}{ }_{2}}
$$

where $P_{i}$ is the partial pressure of species $i$ at equilibrium at temperature, T. The equilibrium considered here occurs at normal atmospheric pressure, 1 [bar], so that:

$$
P_{\text {tot }}=P_{\mathrm{CH}_{4}}+P_{\mathrm{H}_{2}}=1 \text {. }
$$


By solving this equation for the hydrogen partial pressure, and substituting into the pressure relation for the equilibrium constant (Equation 11), a quadratic equation for the methane partial pressure is obtained:

$$
P_{C H_{4}}=\frac{2 K_{e q}(T)+1 \pm \sqrt{\left.2 K_{e q}(T)+1\right)^{2}-4 K_{e q}(T)^{2}}}{2 K_{e q}(T)}
$$

Calculation of $\mathrm{K}_{e q}$ at temperature $\mathrm{T}$ is achieved by first calculating $\mathrm{K}_{e q}$ at the standard temperature, $298 \mathrm{~K}$, from tabulated values of the Gibbs free energy of formation:

$$
K_{e q}^{\circ}=\exp \left(\frac{-\Delta G_{f C H_{4}}^{\circ}}{R \cdot T}\right)
$$

where the ${ }^{\circ}$ superscript indicates values at standard state, $\mathrm{R}$ is the universal gas constant, equal to $8.314 \mathrm{E}-3[\mathrm{~kJ} / \mathrm{mol} \cdot \mathrm{K}]$, and the standard Gibb's free energy of formation of methane is 50.87 $[\mathrm{kJ} / \mathrm{mol}]$ at $\mathrm{T}_{\text {ref }}=298 \mathrm{~K}$. From the standard-state equilibrium constant, the equilibrium constant at the temperatures of interest, 500 and $1100 \mathrm{~K}$, can be estimated by the van't Hoff relation integrated under the approximation of a constant heat of reaction:

$$
K_{e q}(T)=K_{e q}^{\circ} \exp \left(\frac{\Delta H_{f}^{\circ}}{R}\left(\frac{1}{T_{r e f}}-\frac{1}{T}\right)\right),
$$

where $\mathrm{T}$ is the temperature of interest and the standard formation enthalpy of methane is -74.86 $[\mathrm{kJ} / \mathrm{mol}]$ at $298 \mathrm{~K}$. After calculating this equilibrium constant at the temperature of interest, calculation of the partial pressures is possible (Equation 13); one must consider only the negative root that arises in the quadratic formula in order to furnish meaningful partial pressures.

\section{Equilibrium Pyrolysis Species at $500 \mathrm{~K}$ and $1100 \mathrm{~K}$}

Results for the equilibrium partial pressures, by the calculations outlined above for methane and petroleum and by graph (Figure 5) for the remaining fuels considered, are compiled in Table 3. Note that all fuels were only considered on a dry basis for equilibrium concentration calculations.

Plotting the values from Table 3 for the mole fractions of gaseous products from the $\mathrm{CH}_{x} \mathrm{O}_{y}$ compounds at 500 and $1100 \mathrm{~K}$ (Figures 6 and 7, respectively) reveals the significant changes in the distribution due to the temperature difference.

There is a striking difference in the products at these two temperatures. At $500 \mathrm{~K}$, the product gases composition is dominated by methane and water vapor, while notable amounts of carbon dioxide are also formed from the biomass (to a larger extent) and the coals. Hydrogen production is nearly negligible and carbon monoxide is practically non- 
Table 3: Equilibrium partial pressures [bar] (or mole fractions) at $500 \mathrm{~K}$ and 1100 $\mathrm{K}$ for various solid fuels.

\begin{tabular}{|c|c|c|c|c|c|c|c|c|c|c|}
\hline \multirow[b]{2}{*}{ fuel } & \multicolumn{5}{|c|}{ Equilibrium at $500 \mathrm{~K}$} & \multicolumn{5}{|c|}{ Equilibrium at $1100 \mathrm{~K}$} \\
\hline & $\mathbf{C O}$ & $r \Omega$ & $\mathbf{H}_{2} \mathbf{0}$ & $\mathrm{CH}_{4}$ & $\mathbf{H}_{2}$ & $\mathrm{CO}$ & $\mathbf{C C}$ & $\mathbf{H}_{2} \mathbf{C}$ & $\mathrm{CH}_{4}$ & $\mathbf{H}_{2}$ \\
\hline coal-hvCb & $5.0 \mathrm{E}-06$ & $1.5 \mathrm{E}-02$ & $3.8 \mathrm{E}-01$ & $5.9 \mathrm{E}-01$ & $1.5 \mathrm{E}-02$ & $1.9 \mathrm{E}-01$ & $3.0 \mathrm{E}-03$ & $1.2 \mathrm{E}-02$ & $2.2 \mathrm{E}-02$ & 7.7E-01 \\
\hline coal-hvAb & $3.4 \mathrm{E}-06$ & $6.2 \mathrm{E}-03$ & $2.3 \mathrm{E}-01$ & $7.5 \mathrm{E}-01$ & $1.7 \mathrm{E}-02$ & $1.1 \mathrm{E}-01$ & $1.2 \mathrm{E}-03$ & $9.0 \mathrm{E}-03$ & $2.6 \mathrm{E}-02$ & 8.5E-01 \\
\hline coal-lvb & $2.0 \mathrm{E}-06$ & $2.4 \mathrm{E}-03$ & $1.5 \mathrm{E}-01$ & 8.3E-01 & $1.8 \mathrm{E}-02$ & 7.6E-02 & $5.0 \mathrm{E}-04$ & $6.0 \mathrm{E}-03$ & $2.9 \mathrm{E}-02$ & 8.9E-01 \\
\hline coal-subB & $9.0 \mathrm{E}-06$ & $5.0 \mathrm{E}-02$ & $5.1 \mathrm{E}-01$ & $4.3 \mathrm{E}-01$ & $1.3 \mathrm{E}-02$ & $3.0 \mathrm{E}-01$ & $7.1 \mathrm{E}-03$ & $1.6 \mathrm{E}-02$ & $1.6 \mathrm{E}-02$ & $6.6 \mathrm{E}-01$ \\
\hline coal-ligA & $1.2 \mathrm{E}-05$ & $7.2 \mathrm{E}-02$ & $5.8 \mathrm{E}-01$ & $3.4 \mathrm{E}-01$ & $1.2 \mathrm{E}-02$ & $3.3 \mathrm{E}-01$ & $9.0 \mathrm{E}-03$ & $1.8 \mathrm{E}-02$ & $1.4 \mathrm{E}-02$ & $6.3 \mathrm{E}-01$ \\
\hline brown coal & $1.2 \mathrm{E}-05$ & $7.9 \mathrm{E}-02$ & $5.8 \mathrm{E}-01$ & $3.3 \mathrm{E}-01$ & $1.1 \mathrm{E}-02$ & $3.4 \mathrm{E}-01$ & $9.1 \mathrm{E}-03$ & $1.8 \mathrm{E}-02$ & $1.3 \mathrm{E}-02$ & $6.2 \mathrm{E}-01$ \\
\hline peat & $1.4 \mathrm{E}-05$ & $1.2 \mathrm{E}-01$ & $5.9 \mathrm{E}-01$ & $2.8 \mathrm{E}-01$ & $1.0 \mathrm{E}-02$ & $3.9 \mathrm{E}-01$ & $1.3 \mathrm{E}-02$ & $1.9 \mathrm{E}-02$ & $1.2 \mathrm{E}-02$ & $5.7 \mathrm{E}-01$ \\
\hline biomass-pine & $1.4 \mathrm{E}-05$ & $1.1 \mathrm{E}-01$ & $5.9 \mathrm{E}-01$ & $2.9 \mathrm{E}-01$ & $1.0 \mathrm{E}-02$ & $3.9 \mathrm{E}-01$ & $1.3 \mathrm{E}-02$ & $1.9 \mathrm{E}-02$ & $1.2 \mathrm{E}-02$ & $5.7 \mathrm{E}-01$ \\
\hline biomass-straw & $2.0 \mathrm{E}-05$ & $2.0 \mathrm{E}-01$ & $6.1 \mathrm{E}-01$ & $1.8 \mathrm{E}-01$ & 7.7E-03 & $4.8 \mathrm{E}-01$ & $2.0 \mathrm{E}-02$ & $2.0 \mathrm{E}-02$ & $8.0 \mathrm{E}-03$ & $4.8 \mathrm{E}-01$ \\
\hline methane & $0.0 \mathrm{E}+00$ & $0.0 \mathrm{E}+00$ & $0.0 \mathrm{E}+00$ & $9.8 \mathrm{E}-01$ & $1.5 \mathrm{E}-02$ & $0.0 \mathrm{E}+00$ & $0.0 \mathrm{E}+00$ & $0.0 \mathrm{E}+00$ & $1.6 \mathrm{E}-01$ & $8.4 \mathrm{E}-01$ \\
\hline petroleum & & & & & & & & & & \\
\hline (crude) & $0.0 \mathrm{E}+00$ & $0.0 \mathrm{E}+00$ & $0.0 \mathrm{E}+00$ & $9.8 \mathrm{E}-01$ & $1.5 \mathrm{E}-02$ & $0.0 \mathrm{E}+00$ & $0.0 \mathrm{E}+00$ & $0.0 \mathrm{E}+00$ & $1.6 \mathrm{E}-01$ & $8.4 \mathrm{E}-01$ \\
\hline waste tires & $1.3 \mathrm{E}-06$ & $9.2 \mathrm{E}-04$ & $1.0 \mathrm{E}-01$ & $8.8 \mathrm{E}-01$ & $1.8 \mathrm{E}-02$ & $5.0 \mathrm{E}-02$ & $2.0 \mathrm{E}-04$ & $4.0 \mathrm{E}-03$ & $3.1 \mathrm{E}-02$ & $9.1 \mathrm{E}-01$ \\
\hline carbon $_{(\mathrm{gr})}$ & - & - & - & - & - & - & - & - & - & - \\
\hline
\end{tabular}




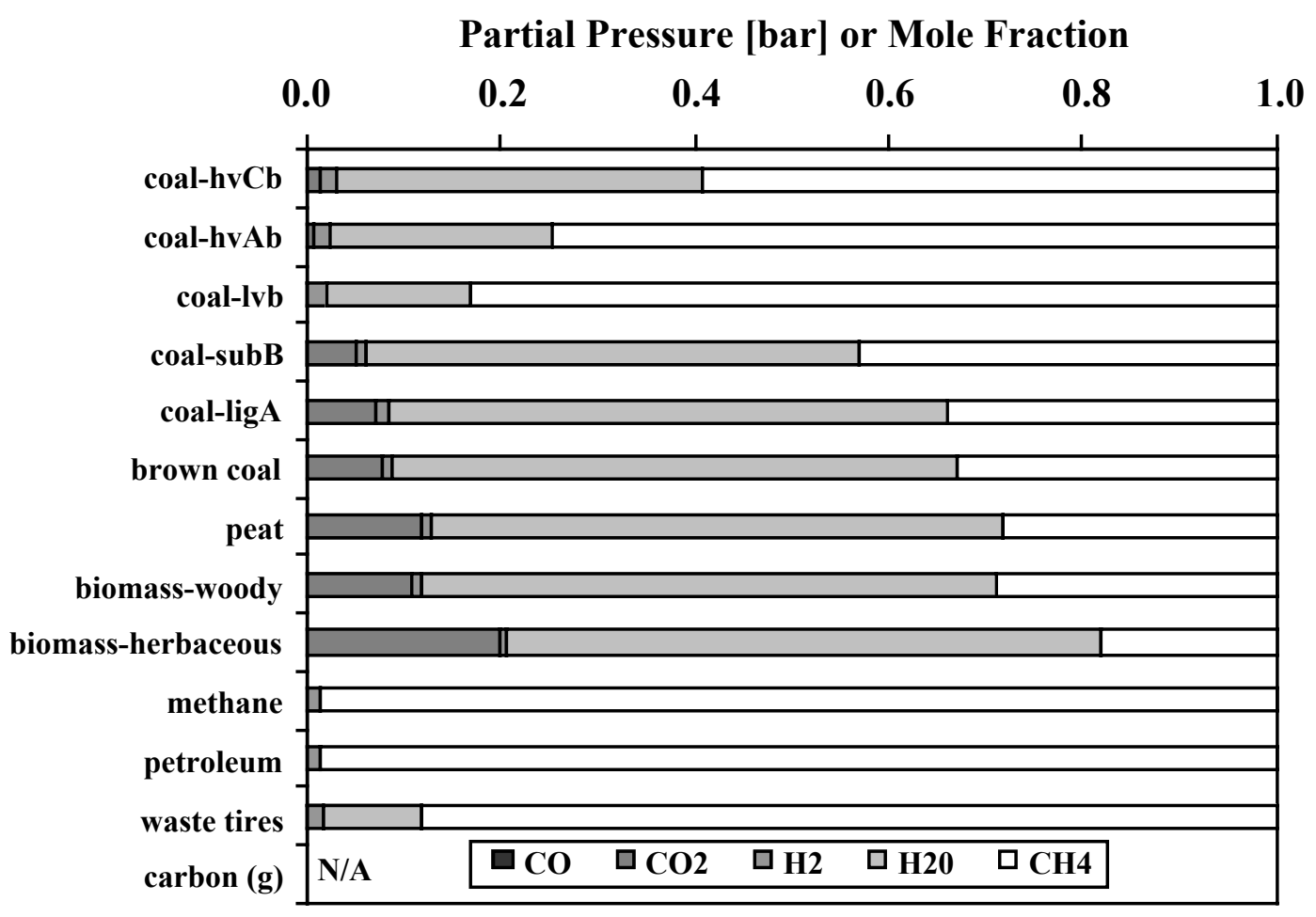

Figure 6: Equilibrium partial pressures [bar] (or mole fractions) at $500 \mathrm{~K}$ for various solid fuels.

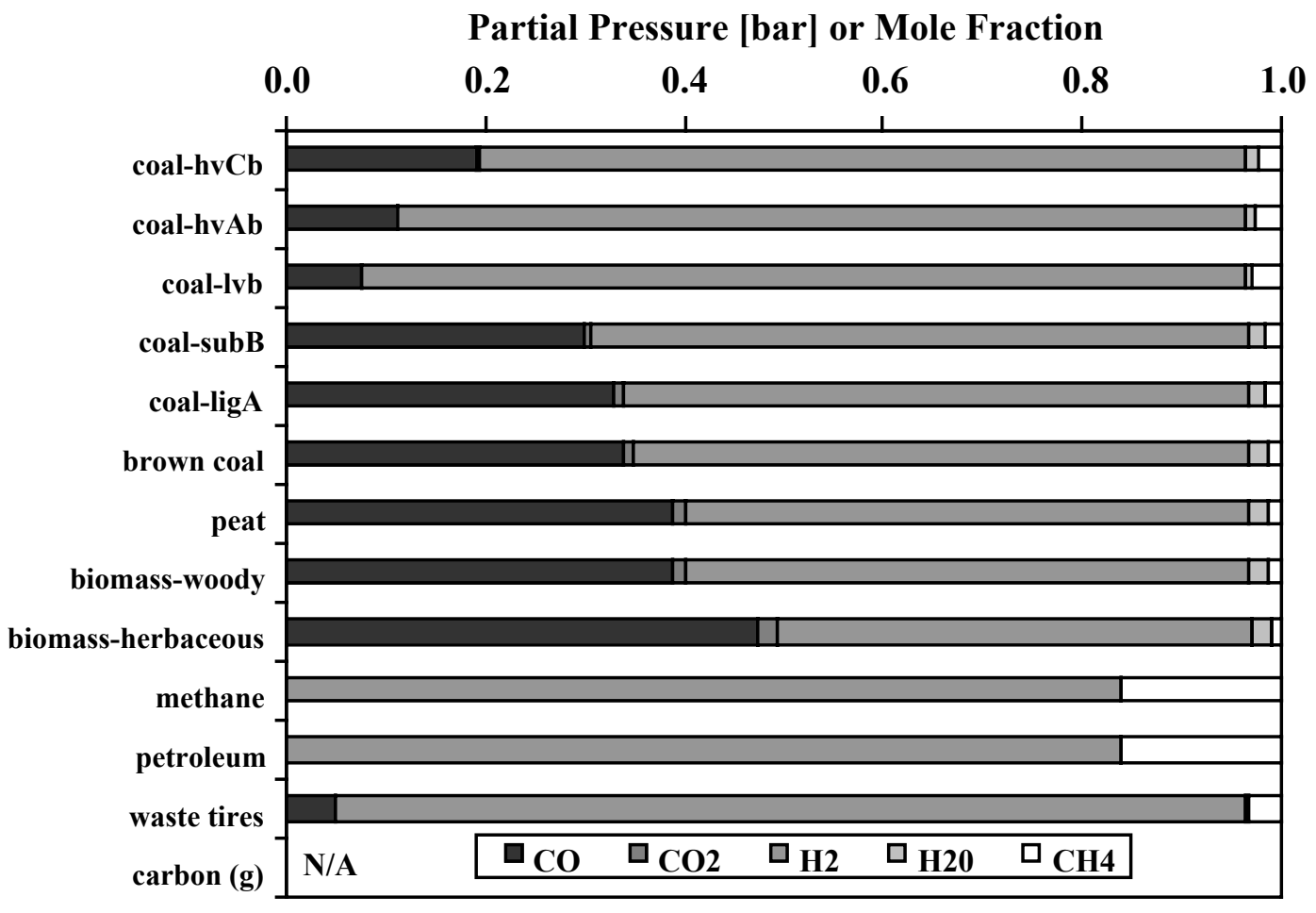

Figure 7: Equilibrium partial pressures [bar] (or mole fractions) at $1100 \mathrm{~K}$ for various solid fuels. 
existent. However, at $1100 \mathrm{~K}$, carbon monoxide production is significant while carbon dioxide amounts diminish. The mixture of gases is dominated at $1100 \mathrm{~K}$ by hydrogen, replacing nearly all the water vapor at $500 \mathrm{~K}$, while suppressing methane production. These differences have a great impact on the evaluation on the oxypyrolysis DCE of a given fuel.

After determining the partial pressures of $\mathrm{CO}, \mathrm{CO}_{2}, \mathrm{H}_{2} \mathrm{O}, \mathrm{CH}_{4}$, and $\mathrm{H}_{2}$ at equilibrium, and noting that the partial pressure in [bar] is equivalent to a mole fraction, a determination of the fixed carbon and volatile yield fractions is possible by considering the conservation of the individual amounts [mol] of carbon, hydrogen, and oxygen. Considering the fuels on a basis of 1 mole, each $\mathrm{CH}_{x} \mathrm{O}_{y}$ compound contains 1 mole of carbon, $x$ moles of hydrogen, and $y$ moles of oxygen. There exists a balance of hydrogen in the fuel with the hydrogen bound in the equilibrium species, all of which contributes to the volatile matter fraction since only carbon is present in the fixed carbon fraction:

$$
x=n_{V M}\left(4 Y_{C_{4}}+2 Y_{H_{2} O}+2 Y_{H_{2}}\right)
$$

where $x$ is the moles of hydrogen present in 1 mole of fuel, as expressed in the $\mathrm{CH}_{x} \mathrm{O}_{y}$ stoichiometric formula, and the $Y$ 's are the mole fractions, equal to the partial pressure of each gas under equilibrium conditions (Table 3). Since these values are known, calculation of $n_{\mathrm{VM}}$, the number of moles of product that exist in the gaseous state as volatile matter, is possible. Similarly, there exists a balance of carbon in the fuel with the both the carbon bound in the equilibrium gaseous species and the carbon that exists as the fixed carbon char:

$$
1=n_{V M}\left(1 Y_{C H_{4}}+1 Y_{C_{2}}+1 Y_{C O}\right)+n_{F C} \text {. }
$$

Since the $Y$ 's are the known mole fractions, equal to the partial pressure of each gas under equilibrium conditions, and $n_{\mathrm{VM}}$ is the number of volatile matter moles, calculated from the hydrogen balance (Equation 16), the number of moles of fixed carbon can also be determined. The fixed carbon moles formed, $n_{\mathrm{FC}}$, can be converted to a mass of fixed carbon, $m_{\mathrm{FC}}$, by multiplication with the molecular weight of carbon. The volatile matter mass, $m_{\mathrm{vM}}$, can be determined by subtraction from the total mass of the original mole of fuel:

$$
m_{F C}=n_{F C} M W_{C}
$$

and

$$
m_{V M}=m_{f u e l}-m_{F C},
$$

where $m_{\text {fuel }}$ is the mass of fuel, here equal to the molecular weight of the fuel. 
Table 4: Volatile matter and fixed carbon percentages as determined by ASTM proximate analysis, equilibrium at $500 \mathrm{~K}$, and equilibrium at $1100 \mathrm{~K}$, on a dry, ashfree basis.

\begin{tabular}{|c|c|c|c|c|c|c|}
\hline \multirow[b]{3}{*}{ fuel } & \multicolumn{4}{|c|}{$500 \mathrm{~K}$} & \multicolumn{2}{|c|}{$1100 \mathrm{~K}$} \\
\hline & wt\% & $\mathrm{wt} \%$ & wt \% & $w t \%$ & wt\% & wt\% \\
\hline & VM & FC & VM & FC & VM & FC \\
\hline coal-hvCb & $45.49 \%$ & $54.51 \%$ & $29.61 \%$ & $70.39 \%$ & $25.27 \%$ & $74.73 \%$ \\
\hline coal-hvAb & $40.14 \%$ & $59.86 \%$ & $28.45 \%$ & $71.55 \%$ & $18.38 \%$ & $81.62 \%$ \\
\hline coal-lvb & $19.20 \%$ & $80.80 \%$ & $21.91 \%$ & $78.09 \%$ & $11.66 \%$ & $88.34 \%$ \\
\hline coal-subB & $47.45 \%$ & $52.55 \%$ & $34.32 \%$ & $65.68 \%$ & $37.69 \%$ & $62.31 \%$ \\
\hline coal-ligA & $62.01 \%$ & $37.99 \%$ & $34.29 \%$ & $65.71 \%$ & $39.65 \%$ & $60.35 \%$ \\
\hline brown coal & $54.64 \%$ & $45.36 \%$ & $41.23 \%$ & $58.77 \%$ & $48.15 \%$ & $51.85 \%$ \\
\hline peat & $62.01 \%$ & $37.99 \%$ & $53.51 \%$ & $46.49 \%$ & $65.73 \%$ & $34.27 \%$ \\
\hline biomass-pine & $78.88 \%$ & $21.13 \%$ & $70.76 \%$ & $29.24 \%$ & $87.70 \%$ & $12.30 \%$ \\
\hline biomass-straw & $80.26 \%$ & $19.74 \%$ & $64.34 \%$ & $35.66 \%$ & $83.84 \%$ & $16.16 \%$ \\
\hline methane & $25.13 \%^{*}$ & $74.87 \%{ }^{*}$ & $99.42 \%$ & $0.58 \%$ & $45.61 \%$ & $54.39 \%$ \\
\hline petroleum (crude) & $13.94 \%^{*}$ & $86.06 \%{ }^{*}$ & $54.94 \%$ & $45.06 \%$ & $25.21 \%$ & $74.79 \%$ \\
\hline waste tires & $70.25 \%$ & $29.75 \%$ & $33.80 \%$ & $66.20 \%$ & $15.29 \%$ & $84.71 \%$ \\
\hline carbon (g) & $0.00 \%$ & $100.00 \%$ & $0.00 \%$ & $100.00 \%$ & $0.00 \%$ & $100.00 \%$ \\
\hline
\end{tabular}

The weight percentages of interest, for percent fixed carbon and for percent volatile matter, can then be determined knowing these masses. Table 4 shows the volatile matter and fixed carbon percentages as determined by equilibrium considerations compared with the percentages determined by the ASTM proximate analysis.

\section{Comparison of ASTM and Equilibrium Oxypyrolysis DCE}

Using the equilibrium compositions at $500 \mathrm{~K}$ and at $1100 \mathrm{~K}$ as opposed to the ASTM standard proximate analysis yields in calculating the DCE has markedly different consequences. The results using equilibrium concentrations are presented in Figure 8 along with the previously reported results from the proximate analysis composition (as in Figure 4) for comparison. 


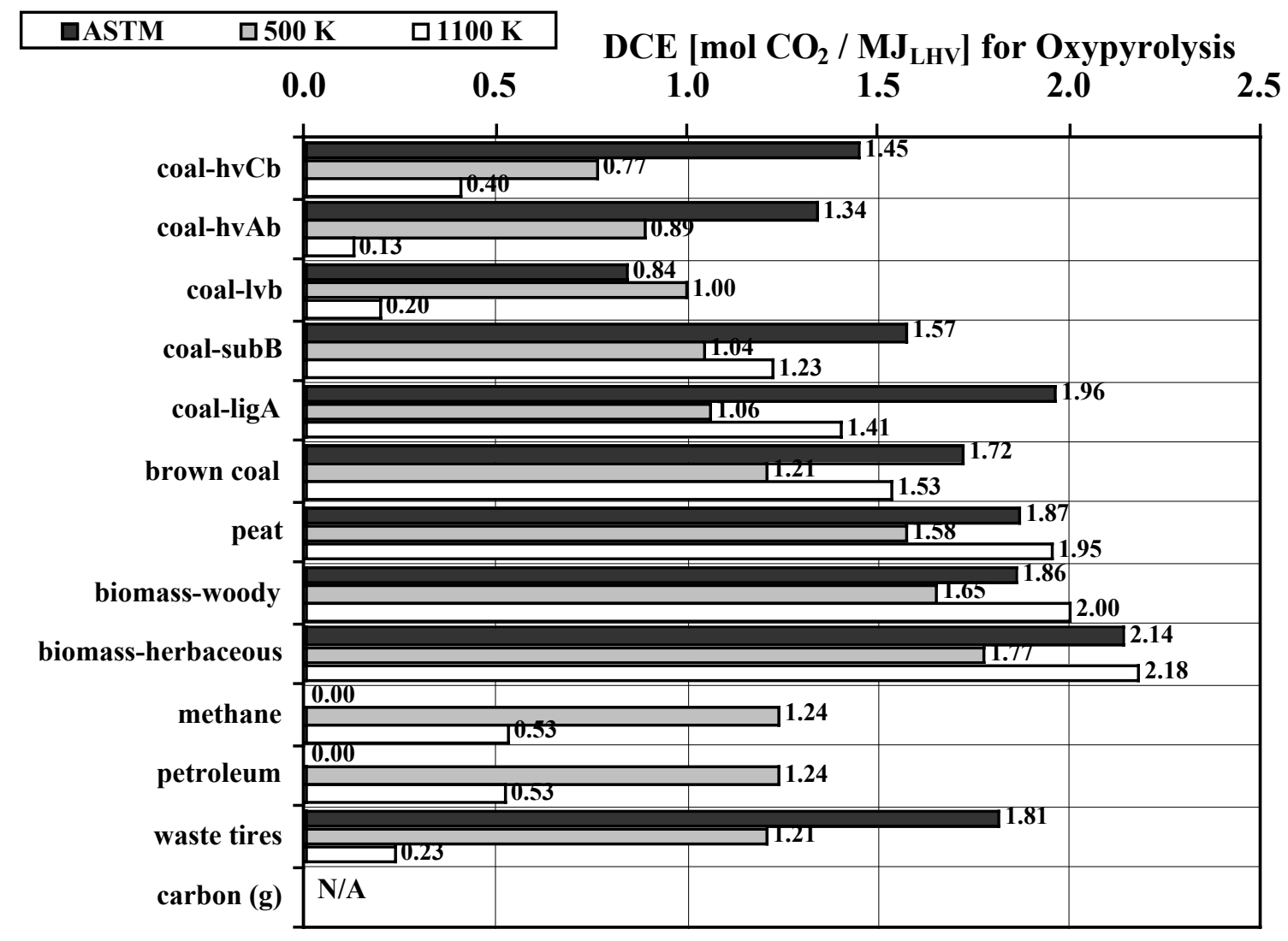

Figure 8: A comparison of Direct Carbon Emissions (DCE) for oxidative pyrolysis using ASTM proximate analysis, $500 \mathrm{~K}$ equilibrium, and $1100 \mathrm{~K}$ equilibrium fixed carbon yields for various solid fuels, on a dry fuel basis.

In general, the DCE for higher rank coals (hvCb, hvAb, lvb) declines significantly when processed at equilibrium conditions, especially at the higher temperature. A similar trend is observed for waste tires, where a nearly $90 \%$ reduction from the combustion DCE is possible using $1100 \mathrm{~K}$ equilibrium conditions. Although it is also preferable to process the lower rank coals (subB, ligA, brown) and peat under equilibrium conditions, it is more favorable to do so at the lower temperature for these fuels. The trends for the woody and herbaceous biomass are a bit more interesting; in both cases, equilibrium conditions produce high DCE at higher temperature but lower DCE at lower temperature. Perhaps the most interesting result, however, is that processing crude petroleum has the same global warming ramifications as processing methane when considering equilibrium conditions, at least at $500 \mathrm{~K}$ and $1100 \mathrm{~K}$. Of the fuels and processes considered here, deriving gaseous and fixed carbon fractions from high-volatile-A bituminous coal under equilibrium conditions at $1100 \mathrm{~K}$ and burning only the volatile matter is a very favorable method for minimizing the global warming impact from direct carbon emissions. This result reflects the fact that these fuels yield very hydrogen-rich volatile matter during high-temperature equilibrium pyrolysis. It should also be recognized that of the three fractionation methods considered here, no one yields the most favorable results among every fuel considered. 


\section{Global Warming Index}

Although the direct carbon emissions are helpful in recognizing trends associated with specific carbon dioxide emissions, alone it gives a very incomplete picture. First, the DCE calculation gives no credit for the renewable nature of some fuels, ignoring the emissions savings associated with regrowth. Second, direct carbon emissions do not account for the mass of fuel to be processed. By relating the emissions per unit of energy, the oxypyrolysis of low-volatile bituminous coal, for example, looks favorable, but would, in practice, require the handling of enormous amounts of fuel. Additionally, there is no consideration of electricity production rather than heat production, nor of the variability among the fuels in their respective thermal efficiencies.

For these reasons, one can gain more insight by considering another index, which measures the impact of switching fuels and/or processes on a mass basis. The Global Warming Index (GWI), defined as:

$$
G W I=\frac{\Delta n_{\mathrm{CO}_{2}}}{m_{a f}}
$$

where $\Delta n_{\mathrm{CO} 2}$ is the change in moles of carbon dioxide emitted and $m_{\mathrm{af}}$ is the mass of alternate fuel. The GWI indicates the net change in total $\mathrm{CO}_{2}$ emissions from all sources when an alternate fuel and process combination is used as a substitution for a pre-defined baseline fuel and process combination, chosen here to represent current practices. The term "alternate fuel," rather than "alternative fuel," is used herein to distinguish between the baseline and substitute fuel and process combination.

\section{Thermal Global Warming Index Considerations}

When considering heat production processes the GWI can be written in terms of the DCE discussed above:

$$
G W I_{\text {thermal }}=(D C E \Delta h)-\left(D C E_{\text {baseline }} \Delta h\right)-G D I,
$$

where $\Delta \mathrm{h}$ is the net energy produced by the fuel and process combination under consideration per unit mass of alternate fuel and GDI accounts for any fuel's (G)rowth or (D)ecay (I)mpact. The first term on the right-hand-side of equation 21 can be considered the "direct" carbon dioxide emissions, resulting from the alternate fuel processing. The remaining two terms contribute to the "indirect" global warming impact, resulting from: (1) the replacement of the baseline fuel processing method $\left(\mathrm{DCE}_{\text {baseline }} \cdot \Delta \mathrm{h}\right)$, and (2) from decay or re-growth processes associated with renewable fuel sources (GDI).

\section{Baseline Energy Production}

The replacement of the baseline fuel process by an alternate one requires that a fixed energy demand be met. That is, although the thermal GWI reflects the emission changes on a fuel alternative mass basis, the calculation is performed by considering replacement of the baseline fuel on an equal energy basis. In this case, $\sigma=1$, since there is a unit of baseline heat energy replaced 
for every unit of heat energy produced by the alternate method. Alternatively, then, the GWI for heat production can be written as:

$$
G W I_{\text {thermal }}=\Delta h\left(D C E-D C E_{\text {baseline }}\right)-G D I .
$$

The grouped terms can be viewed as the change in combustion emissions from the baseline method. In this form, one can easily recognize that using an alternate fuel with a DCE value greater than that of the baseline fuel will have a detrimental impact on carbon dioxide emissions, unless there are significant growth or decay considerations. The two baseline processes considered here are:

- bituminous coal (hvAb) combustion, as widely practiced for electricity generation in many parts of the U.S., and

- natural gas combustion, which is the dominant fossil power source in some regions in the U.S.

The last term of the equation, GDI, deserves special consideration. Through this growth and decay impact value, two important factors are quantified:

- the renewable nature of many biomass fuels, and

- the effects of natural decay.

Full understanding of these two terms prompts the differentiation between energy crops and agricultural wastes. The steady-state condition of energy crops, where rapid-growth wood groves (poplar, for example) are repeatedly grown, harvested for energy use, and re-planted, is assumed here to be part of the baseline condition. During continuous operation, energy crops have no net contribution to carbon dioxide emissions since carbon dioxide emitted during complete combustion of the wood material is neutralized by the re-growth of another tree in its place. If oxidation of the fuel carbon is not complete, as is the case for pyrolysis, there will be a net effect on the total carbon emissions.

Unlike plant material from energy crops, agricultural residues are by-products of other residential, commercial, or industrial practices. The residues may be wood form, as sawdust is a by-product of lumber practices, in nut or shell form, as olive pits or almond shells are by-products of some food services, or in herbaceous form, as cornhusks and rice hulls are discarded before use. The disregard of these wastes, leading to natural biological decay, is assumed for the baseline condition here. Any use of the residues, avoiding the decay, will have an effect on carbon dioxide emissions that must be considered.

In equation form, these contributions are additive:

$$
G D I=P C F+A B D
$$

where $\mathrm{PCF}$ is $(\mathrm{P})$ hotosynthetic $(\mathrm{C})$ arbon $(\mathrm{F})$ ixation occurring during regrowth, and $\mathrm{ABD}$ accounts for (A)voided (B)iological (D)ecay in the baseline. PCF allows credit to be given for the renewable 
nature of some fuels, reflecting the photosynthetic removal of atmospheric carbon dioxide into carbon, existing in the re-grown plant, and exhausted oxygen. This term accounts for the effect of clearing plants from a land area, where there would then be an immediate availability of land and light, stimulating re-growth. This re-growth process is characterized by removal of carbon dioxide from the atmosphere via photosynthesis, providing the carbon reflected in the plant's ultimate analysis.

If the fuel considered is a waste product, the possible natural biological decay of the plant material is considered part of the baseline condition. The decay process essentially has an effect opposite to that of re-growth; during decay, the carbon of the raw waste material is converted either aerobically to form primarily carbon dioxide, or anaerobically to form primarily methane, an even more potent greenhouse gas. The avoidance of this process, then, causes reductions in emissions from the baseline condition, and is quantified through the ABD term.

\section{Time Scales of Global Warming, Energy Production, and Natural Decay}

Another important factor in the determination of the Global Warming Index is the time scale on which the carbon dioxide emissions should be considered. As was discussed when introducing this topic, the efforts and suggestions of the IPCC are focused to combat the predicted temperature rise within the beginning of this new century. Possible gaseous emissions production and savings will only be considered if the time scale over which they occur is less than a half-century.

All of the emissions associated with energy production or savings by combustion or by oxypyrolysis occur on the time scale of typical furnaces, either seconds or minutes, no matter the fuel type. Natural decay, in contrast, is highly dependent on the fuel being considered. Specifically, coal, peat, wood, herbaceous growth, and waste tires all have different characteristic times for natural decay. Coal has existed as a stable earth material for millions of years, and is expected to continue to do so for millions more; no consideration for its decay is given here. Although rubber products are certainly susceptible to decay, mainly through ultraviolet exposure, waste tires have been found to decay very slowly compared to other landfilled materials [Kemkar, 2001] and, consequently, its extent of decay is considered here to be minimal over the time frame of interest. The analysis of peat decomposition is made difficult by peat's dual nature, acting as a metamorphosized plant product in its oldest forms while also existing as simply a wet grass during its normal growth period. In addition, there has been recent report of the possibility of peatland bogs to store carbon [Freeman, et al., 2001]. However, this effect was only recorded for isolated regions, and is expected to diminish significantly within the near decades considered for global warming, justifying its absence from quantification here.

Other plant life, however, has been found to have characteristic natural decay times on the order of a few weeks to several years [Zabel and Morrell, 1997]; their decay times are highly dependant on the conditions that promote decay. Not only do the decay times differ for different plant species, but also the time needed for significant decay is also highly dependant on the type of fungi that attacks the wood or plant. Some fungi, specifically white rots, are capable of completely degrading a wood product, accomplishing 96-97\% weight loss, while other decay fungi only attack the portions of the wood cell walls, resulting in weight losses on the order of 60 to 70 percent [Zabel and Morrell, 1997]. Of course, natural decay is highly dependent on the presence of necessary moisture and energy for the process. As an example, Figure 9 illustrates the widely varying propensity for aboveground decay of wood products across the United States. 


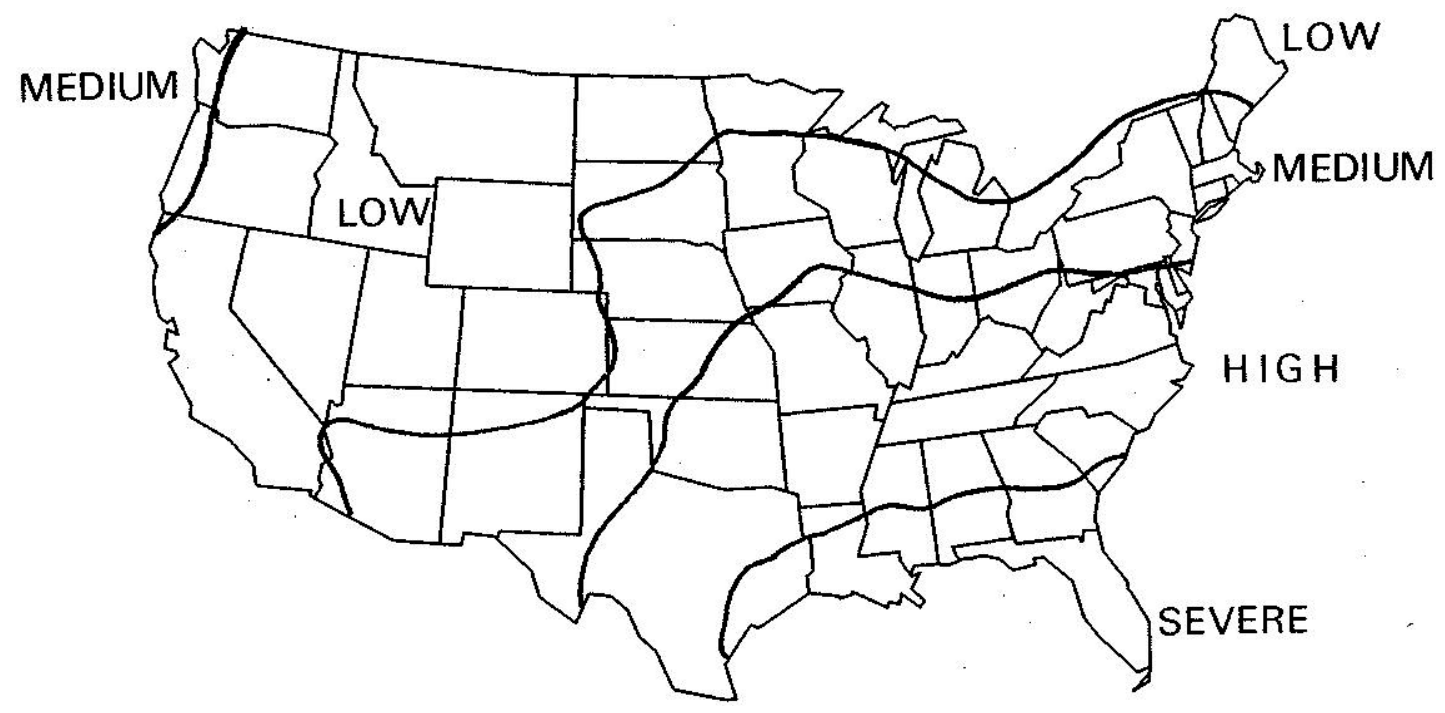

Figure 9: Decay hazards for aboveground exposure of wood products in the United States (from Zabel \& Morrel, 1997, p. 346)

The most obvious trend suggested by the decay hazards map is the strong dependence on moist conditions, exemplified by the Gulf States. Additionally, the type of decay process, aerobic or anaerobic, plays a role in the influence of natural decay on greenhouse gas emissions. Specifically, the products of aerobic decay are primarily $\mathrm{CO}_{2}$ and $\mathrm{H}_{2} \mathrm{O}$, while anaerobic decay promotes the formation of $\mathrm{CH}_{4}$, a more potent greenhouse gas, rather than $\mathrm{CO}_{2}$. Aerobic decay is assumed for the present study.

Regardless of the variability of characteristic natural decay times among plant species, it is reasonable to consider a typical decay time for wood and herbaceous biomass to be smaller than the half-century timescale of interest for global warming. In fact, complete degradation of a plant product is possible within twenty weeks [Zabel and Morrell, 1997] under certain conditions. In the calculation of the Global Warming Index, woody and herbaceous biomass have been credited with $\mathrm{CO}_{2}$ savings resulting from prevention of carbon dioxide emissions from this natural decay process.

\section{Carbonization}

Another interesting feature of the Global Warming Index comes as a result of comparing fuel and process combinations to the baseline condition. Unlike the DCE, the GWI allows one to consider processes during which no energy is extracted, yet during which the availability of fuel carbon to form carbon dioxide is altered. As shown previously, separating a carbonaceous fuel into its volatile compounds and its fixed carbon fraction (and mineral matter, of course), and subsequently combusting only the volatiles can reduce the amount of carbon dioxide emitted per unit of energy produced. This oxypyrolysis method of energy extraction was found to be more attractive, environmentally speaking, whether the ASTM standard, $500 \mathrm{~K}$ equilibrium, or $1100 \mathrm{~K}$ equilibrium yields was used to represent the fractionation of the fuel. However, as environmentally sound as this investigation would suggest, oxypyrolysis is often not a feasible process in areas where waste fuel scraps (wood, grass, tires, etc.) are produced but there is no need for thermal energy. Waste 
wood in remote regions may be used for charcoal production by primitive earth pit burning while oxypyrolysis or combustion is not feasible. In such scenarios, although energy extraction is not possible, carbonization, or simple pyrolysis, may still be beneficial for global warming. Because it prevents total degradation of the carbon backbone to carbon dioxide via natural decay, carbonization will always realize some greenhouse gas reduction compared to natural decay. This concept, referred to throughout as "carbonization", was investigated along with oxypyrolysis and combustion for the GWI calculations.

\section{GWI $_{\text {thermal }}$ for Combustion Processes}

Calculation of the GWI, as one will recall, is dependent on the definition of the baseline fuel process, the carbonaceous alternate fuel in question, the thermochemical process in question, and, in the case of oxypyrolysis and of carbonization, the means by which the fractionation of the fuel into fixed and volatile portions is considered. Additionally, calculating the results on a dry- or wet-fuel basis will also affect the results. Perhaps the simplest of these alternative fuel process arrangements is co-firing, the combustion of more than one fuel in a single furnace. During this process, energy from the baseline fuel combustion is replaced by an equal amount of energy from the alternate fuel combustion.

Depending on the lower heating value of both fuels, the amount of fuel replaced from the baseline may differ from the amount of alternate fuel used as a replacement, but the one unit of energy "demand" that results from removal of some baseline fuel is always replaced by the equivalent unit of energy "supply" from the addition of the alternate fuel. As a result, there is a change in the amount of $\mathrm{CO}_{2}$ produced by the system per mass unit of alternate fuel used. Combining Equations 22 and 23 gives:

$$
G W I_{\text {thermal }}=\Delta h\left(D C E-D C E_{\text {baseline }}\right)-(P C F+A B D)
$$

where, for combustion, _h is equal to the LHV of the alternate fuel and non-zero values for PCF and $\mathrm{ABD}$ are only given for woody and herbaceous biomass. Of course, considering the GWI on a wet fuel basis requires use of DCE, LHV, PCF, and ABD on a wet fuel basis rather than a dry fuel basis.

Mathematically accounting for photosynthetic carbon fixation (PCF) and for avoided biological decay $(\mathrm{ABD})$ differs slightly, depending on the time scale for the natural decay process and whether a biomass fuel is a waste material or harvested from an energy crop:

$$
\begin{gathered}
\text { energy crop: } P C F=\frac{w t \% C / 100}{M W_{C}}, \quad A B D=0 \\
\text { rapidly decaying waste material: } P C F=0, \quad A B D=\frac{w t \% C / 100}{M W_{C}}
\end{gathered}
$$

slowly decaying waste material: $P C F=0, A B D=0$ 


\section{$G W I_{\text {thermal }}$ Values for Combustion}

Figures 10 and 11 show that, for the bituminous coal and natural gas (methane) baselines, respectively, the effects of considering the GWI on a wet basis versus a dry basis are not significant compared to the effect of the variation of fuel type or choice of baseline fuel.

It is important to bear in mind that, unlike the DCE indicator, which is never negative but reflects more advantageous fuels through smaller positive values, the GWI can be positive or negative, the latter reflecting advantageous alternatives by that decrease carbon dioxide emissions for the entire system. Considering a high-volatile-A bituminous coal baseline (Figure 10), it is clear that replacement of the coal combustion process by switching to other coals or co-firing with peat is not desirable because of their positive GWI, whether considered on a wet or dry basis. As suggested by the previous DCE results, char co-firing is the worst option, due to the high direct carbon

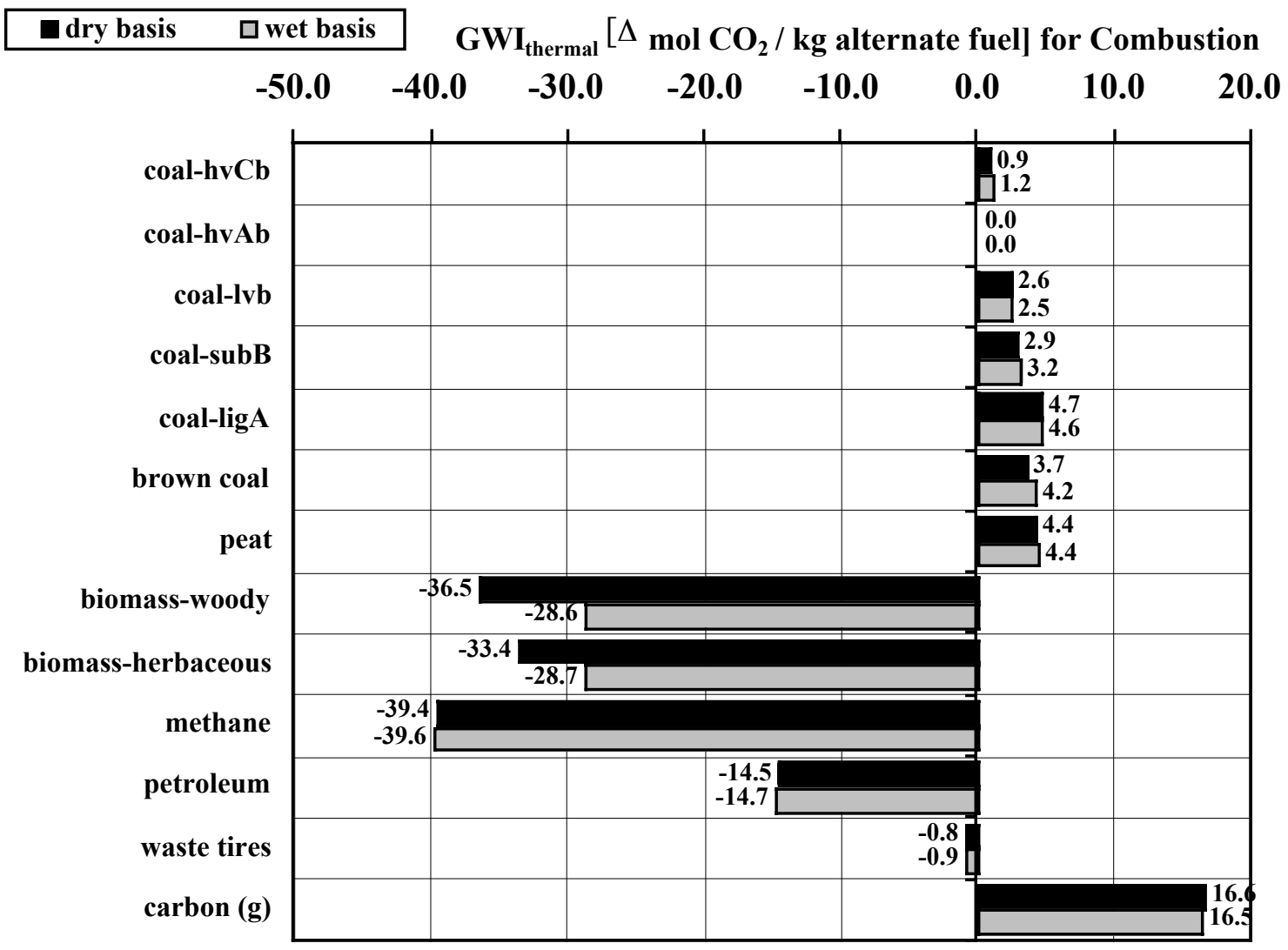

Figure 10: Global Warming Index values on a thermal basis for the combustion of various fuels as an alternative to hvAb coal combustion.

emissions of elemental carbon. Co-firing any of the other fuels with coal is beneficial, reflected in the negative values of GWI. Co-firing biomass is particularly advantageous, with large, negative GWI values. Although the co-firing of waste tires is marginally beneficial for global warming, it 
would have the additional environmental advantage of reducing landfill volume. Considering the two biomass types and methane, one can see the significant effect of preventing natural decay of the plant materials, making co-firing of biomass wastes almost as attractive as fuel-switching to methane, an effect that is not obvious from the DCE results, but is well known in the energy industry.

Figure 11 shows the same calculation but with natural gas as the baseline fuel. As with earlier results, including fuel moisture does not significantly change the trends in Figure 11. The most significant result shown above is the indication of a net reduction in $\mathrm{CO}_{2}$ emissions by the combustion of biomass, compared with the detrimental increase in emissions from the combustion of all other fuels considered. These results make clear that in a natural gas energy production environment, there is a considerable advantage to combusting biomass wastes rather than allow them to naturally decay, while it is better for all non-renewable solid fuels to be left alone. Again, the combustion of char would dramatically increase the amount of $\mathrm{CO}_{2}$ emitted to meet a particular energy demand. Avoiding fixed carbon combustion by oxypyrolysis, then, seems a promising option.

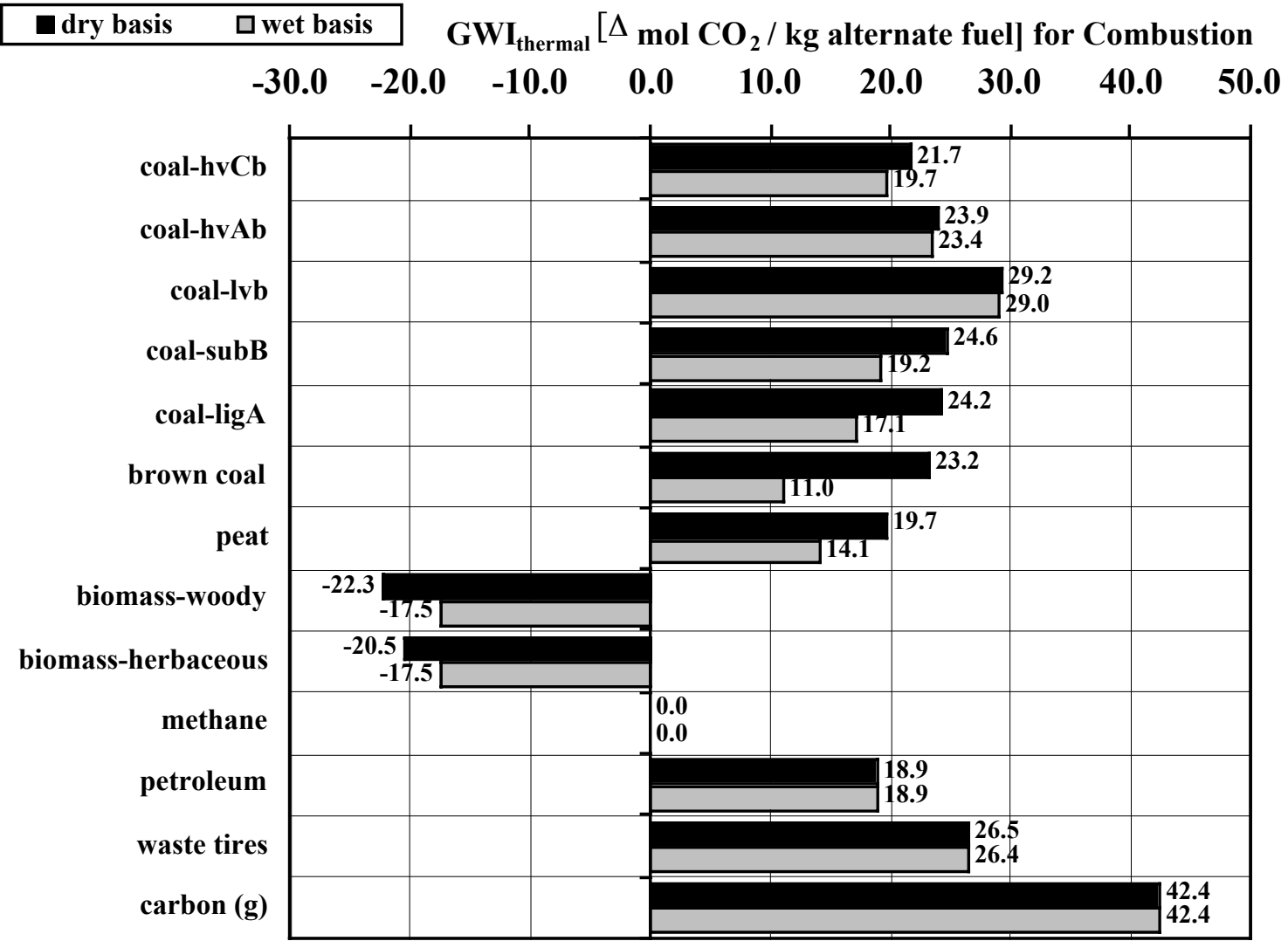

Figure 11: Global Warming Index values on a thermal basis for the combustion of various fuels as an alternative to natural gas (methane) combustion. 


\section{GWI $_{\text {thermal }}$ for Oxypyrolysis}

Figures 12 and 13 reflect the thermal GWI values for oxypyrolysis in the coal and gas baselines, respectively. As was the case in determining the DCE, calculating the GWI for oxypyrolysis differs slightly from that of simple combustion. Equation 25 for the combustion GWI can be used to calculate the oxypyrolysis GWI by using the appropriate DCE value for oxypyrolysis for the alternate scenario, while the DCE value for the baseline is still that for combustion. The heat evolved during the alternate process, $\mathrm{h}$, comes only from the combustion of the volatiles, so that, for oxypyrolysis:

$$
\Delta h=L H V-\frac{w t \% F C}{100} L H V_{C}
$$

where the un-subscripted LHV refers to the alternate fuel.

The terms for the Growth and Decay Impact are treated exactly as they were for combustion. The value for fixed carbon weight percent can be determined by the ASTM

\section{GASTM $\square 500 \mathrm{~K} \quad \square 1100 \mathrm{~K}] \mathrm{GWI}_{\text {thermal }}\left[\Delta_{\mathrm{mol} \mathrm{CO}} / \mathrm{kg}\right.$ alternate fuel] for Oxypyrolysis}

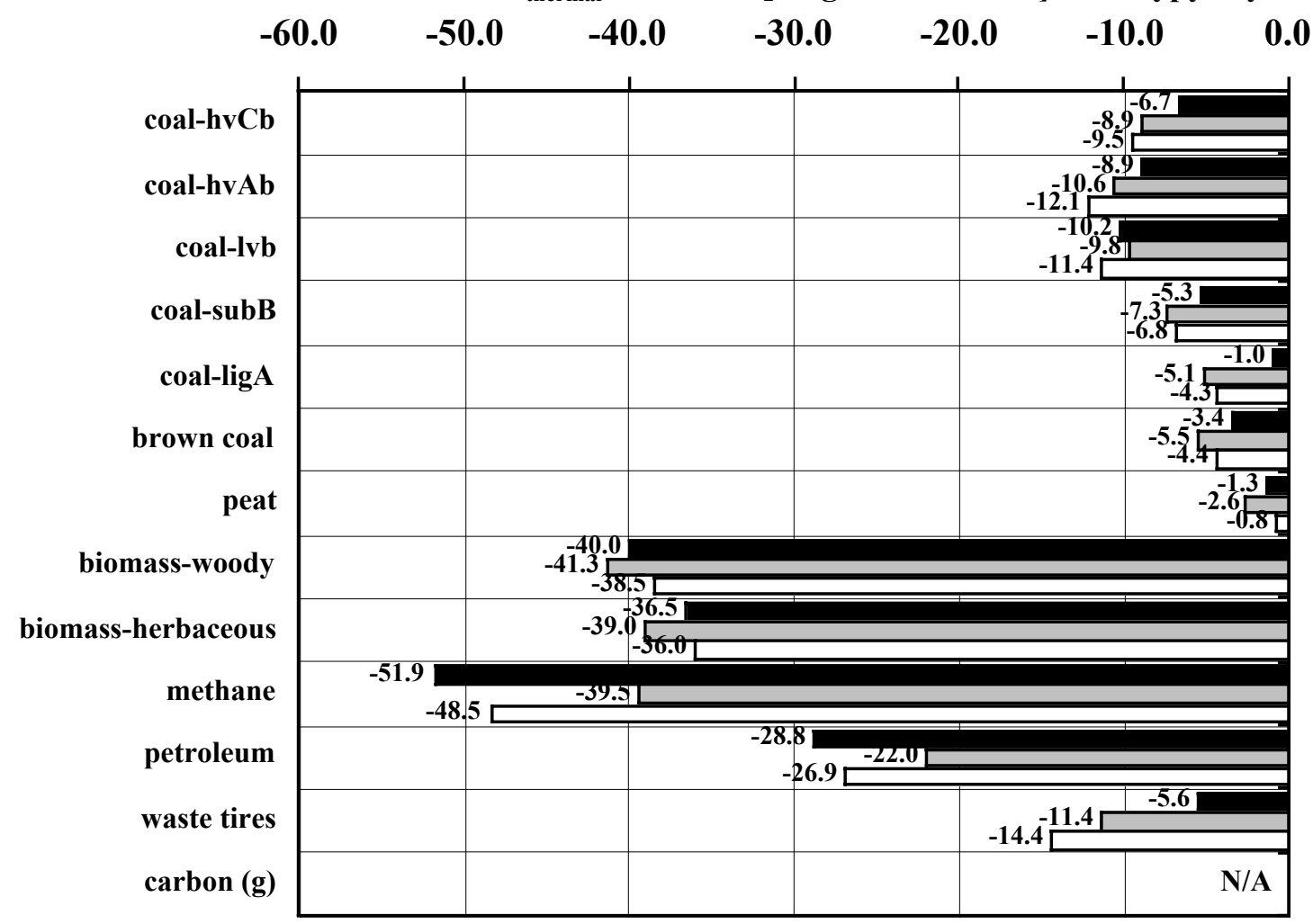

Figure 12: Global Warming Index values on a thermal basis for the oxidative pyrolysis of various fuels as an alternative to hvAb coal combustion, on a dry basis. 
standard proximate analysis, or by equilibrium considerations at a given temperature. Here, the yields from proximate analysis, equilibrium at $500 \mathrm{~K}$, and equilibrium at $1100 \mathrm{~K}$ are again considered.

\section{$G W I_{\text {thermal }}$ Values for Oxypyrolysis}

Results for the oxypyrolysis GWI are only considered on a dry basis, as the effects of moisture are small compared with effects of the choice of baseline and alternate fuel type. Considering the coal baseline (Figure 12), the advantage of oxidatively pyrolyzing any fuel is clear; no matter the method used to determine the fixed carbon percentage, there will be a net decrease in carbon dioxide emissions for every mass unit of alternate fuel processed. The fact that it is beneficial to replace coal combustion with oxidative pyrolysis of any fuel is expected, as oxidative pyrolysis avoids combustion of the char, the worst fuel for direct carbon dioxide emissions.

Although the oxypyrolysis of coals is an attractive option compared to the high-volatile bituminous coal combustion, the benefits of processing the renewable biomass energy sources in this manner are even greater. This alternative combines the benefits of oxidative pyrolysis and prevention of the biomass decay. Figure 12 illustrates that methane use is superior to other fuels, but the magnitude

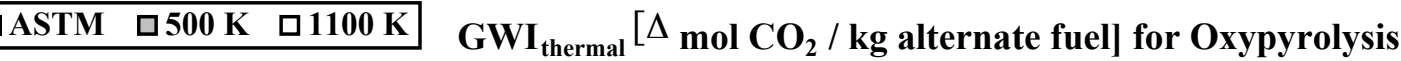

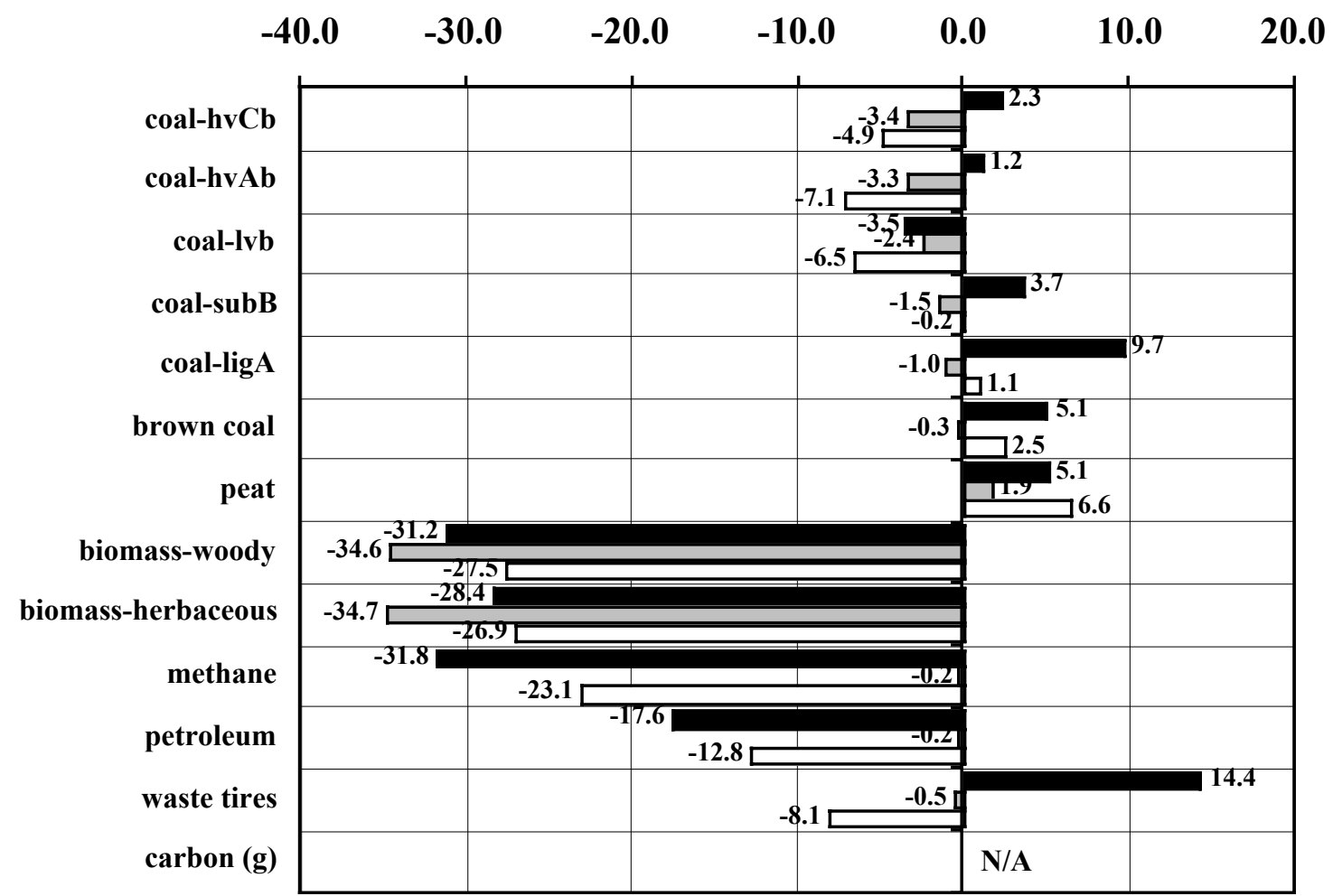

Figure 13: Global Warming Index values on a thermal basis for the oxidative pyrolysis of various fuels as an alternative to natural gas (methane) combustion, on a dry basis. 
of the advantage is dependent on the pyrolysis method. The most striking trend here, however, is that no matter the method used for fixed carbon percentage determination, the oxidative pyrolysis of biomass wastes as an alternative to coal combustion can significantly reduce carbon dioxide emissions. Waste tire scraps produce a similar, but noticeably smaller effect.

The results of the natural gas baseline (Figure 13) reflect the importance of choosing the baseline environment and of the pyrolysis process for determining the fixed carbon percentage. First, when considering natural gas combustion rather than coal combustion as the baseline energy production process, it becomes more difficult to justify any alternate fuel or process. The results from equilibrium yields at $500 \mathrm{~K}$ and $1100 \mathrm{~K}$ still suggest that replacing natural gas combustion with coal oxypyrolysis is slightly advantageous, while the results from the ASTM proximate yields a slight disadvantage. This effect is also apparent when considering processing waste tires as the alternative. Not surprisingly, to oxidatively pyrolyze methane or petroleum, or to completely crack the carbon and burn the resulting hydrogen-rich fuel in these cases, is a better process than simple methane combustion. The interesting result, however, is that, even in a natural-gas-burning environment, oxidative pyrolysis of woody or herbaceous biomass wastes or energy crops can be far better for global warming than even baseline natural gas combustion. The benefits are not as great as in a coal-burning environment, but the improvements are significant nevertheless.

The results so far have shown that subjecting waste products to combustion or oxypyrolysis is an environmentally better alternative to traditional coal combustion, especially in the case of biomass where natural decay is avoided. In certain arrangements, however, there is inherent complexity associated with co-processing liquid/vapor fuels with solid fuels. For example, replacing natural gas combustion with biomass combustion is advantageous, but co-firing these fuels gas turbines is not technologically feasible. However, firing gas or biomass in a coal unit, also shown to be favorable, is possible.

\section{Carbonization Technology}

Unlike combustion or oxypyrolysis, which, for practical purposes, require significant investment in equipment and a local need for steam heat or electricity, carbonization can be done remotely using primitive technology and requires little investment of capital or labor and at sites with no steam or electricity infrastructure. In the simplest of terms, carbonization is the production of charcoal from a carbonaceous solid fuel, a concept that has long been exploited by those in underdeveloped regions. Carbonization as a feasible utilization for wood wastes from developing countries has been considered in Nigeria [Dionco-Adetayo, 2001], Kenya [Okello, et al., 2001], and Tanzania [Luoga, et al., 2000], where typically wood is carbonized in earthen pits. As an option for agricultural residue management, sugarcane bagasse carbonization in Brazil [Zandersons, et al., 1999] and hazelnut shell carbonization [Demirba_, 1999] have been found to be attractive alternatives to neglect of the wastes. Studies on the efficiency of the carbonization process, under technologically advanced conditions [Antal, et al., 1996] and under primitive conditions [Ward, et al., 1995] have been published.

In industrialized regions, where the demand for steam or electricity is more probable, carbonization is less likely to be considered as an alternative method of processing combustible wastes. However, in some scenarios, carbonization may be the most beneficial technology for global warming. The attractiveness of the carbonization of biomass wastes, for example, will not only depend on whether 
carbonization is considered as an alternative to coal or to natural gas energy production, but also on whether the energy required is thermal energy or electricity.

\section{GWI thermal $_{\text {for }}$ Carbonization}

Carbonization does not provide energy to replace the baseline energy production, but can still be considered for any situation where the energy demand is satisfied by the baseline method alone. Whether the GWI is positive or negative, then, is enough to suggest whether an abundance of a particular fuel, waste or not, should be carbonized rather than disregarded. Consideration of a particular baseline does not change $\mathrm{GWI}_{\text {thermal }}$, but can affect the desirability of carbonization relative to combustion or oxypyrolysis.

It is necessary, though, to examine the GWI equation (Equation 21) as it applies to carbonization. This form of the equation is not valid, as it depends on a DCE value that cannot be established for carbonization since it is assumed that there is no energy associated with the process $(\Delta \mathrm{h}=0)$. However, through multiplication of the DCE in the general form (Equation 1) with $\Delta \mathrm{h}$, the GWI equation for carbonization can be written in the form:

$$
G W I_{\text {carbonization }}=n_{\mathrm{CO}_{2}}-G D I,
$$

where $n_{\mathrm{CO} 2}$ is the number of moles of $\mathrm{CO}_{2}$ released during carbonization per unit mass of fuel:

$$
n_{\mathrm{CO}_{2}}=\frac{(w t \% C-w t \% F C) / 100}{M W_{C}} .
$$

The growth and decay term (GDI) is calculated for the appropriate fuels exactly as it was for combustion and oxypyrolysis.

\section{GWI $I_{\text {thermal }}$ Values for Carbonization}

Figure 14 clearly shows the GWI values for simple carbonization. Using any of the fixed carbon yields considered, carbonization of coals, peat, waste tires, methane, and petroleum is undesirable. In ordinary terms, the results reflect the inherent stability of these fuels toward natural decay. In contrast, the GWI reveals the benefits of carbonizing biomass when energy extraction techniques are unavailable or there is no local need for thermal energy. The variations in the GWI with the method by which the biomass can be carbonized (i.e. ASTM proximate analysis conditions versus equilibrium conditions) do not affect the environmental appeal of carbonizing these wastes, but rather suggests that optimal conditions for the process should be sought.

\section{Comparison of $G W_{\text {thermal }}$ Values for Combustion, Oxypyrolysis, and Carbonization}

Additionally, a direct comparison of the GWI results for the three processes considered here (combustion, oxypyrolysis, and carbonization) allows recognition of the potential impact each has on detrimental carbon dioxide emissions (Figures 15 and 16). In these figures, the ASTM proximate analysis method is used to characterize oxypyrolysis and carbonization. This comparison reveals that in either baseline, coal or natural gas combustion, thermochemically processing biomass 
wastes, either as an alternative to their natural decay, or as an energy crop, for these purposes can significantly reduce carbon dioxide emissions.

In fact, of all the scenarios for these figures, only the oxypyrolysis of methane as an alternative to coal or natural gas combustion can produce more carbon dioxide savings per unit mass than processing biomass wastes. The emissions reduction afforded by biomass waste processing is slightly greater in the high-volatile bituminous coal environment (Figure 15) than in a natural gas

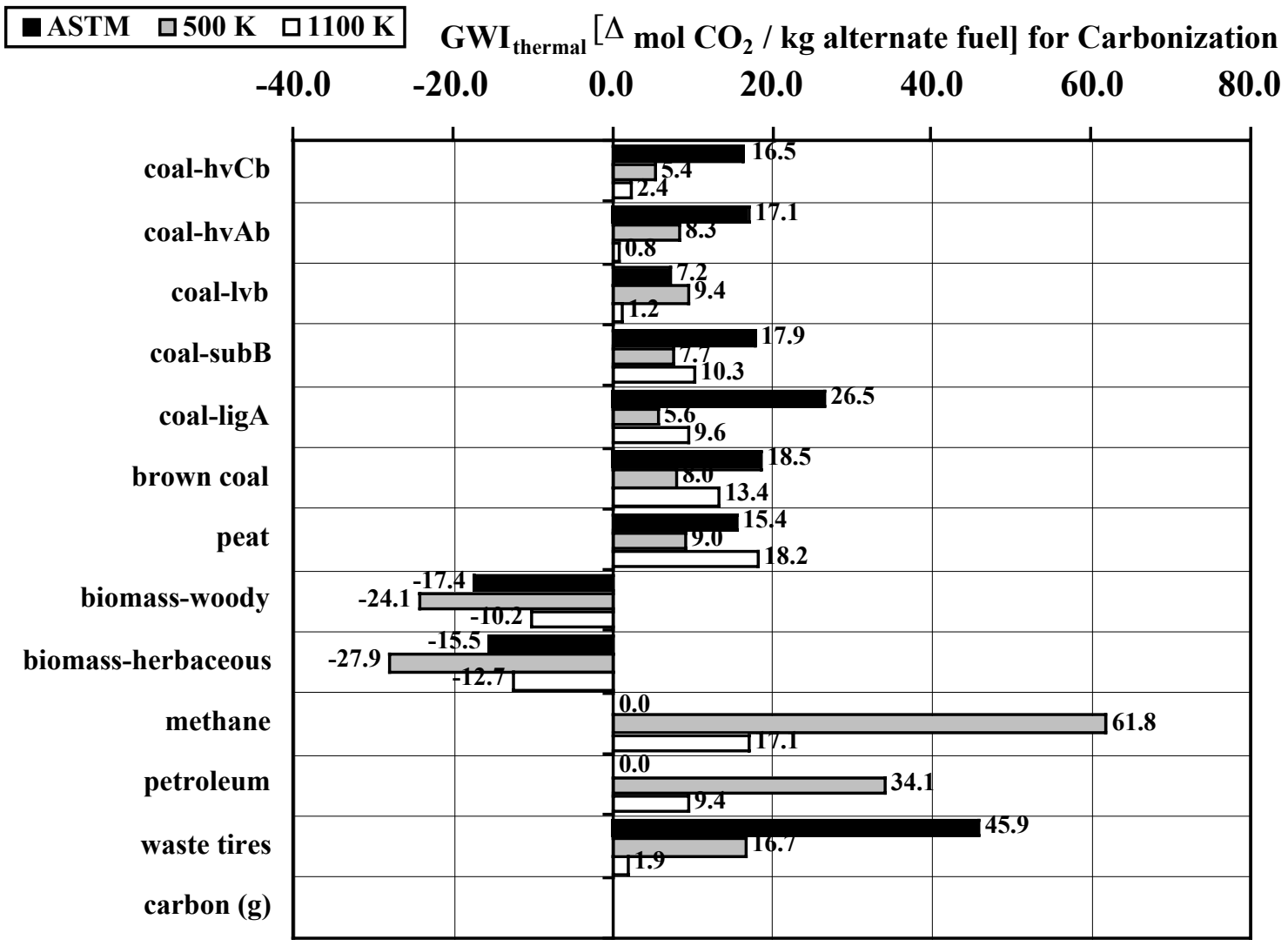

Figure 14: Global Warming Index values on a thermal basis for the carbonization of various fuels, on a dry basis.

environment (Figure 16), but the reduction is significant in either case. The choice of the ASTM results for comparison of oxypyrolysis and carbonization with combustion is a practical one; one should bear in mind that further optimization may be possible by equilibrium methods, as suggested by previous results.

Considering only favorable alternatives to baseline energy consumption, those with negative $\mathrm{GWI}_{\text {thermal }}$ values, there is a definite dependence on the baseline method being replaced. As an alternative to coal combustion, a general trend of favorability among the three technologies exists: 
For the coals, only oxypyrolysis is favorable, while for biomass both oxypyrolysis and combustion are significantly more favorable than is carbonization, though carbonization still provides an improvement from baseline coal combustion. As an alternative to natural gas combustion, however, the favorability of biomass technologies falls more greatly with oxypyrolysis compared to the other 2 technologies:

$$
\text { oxypyrolysis >> combustion > carbonization (natural gas combustion baseline). }
$$

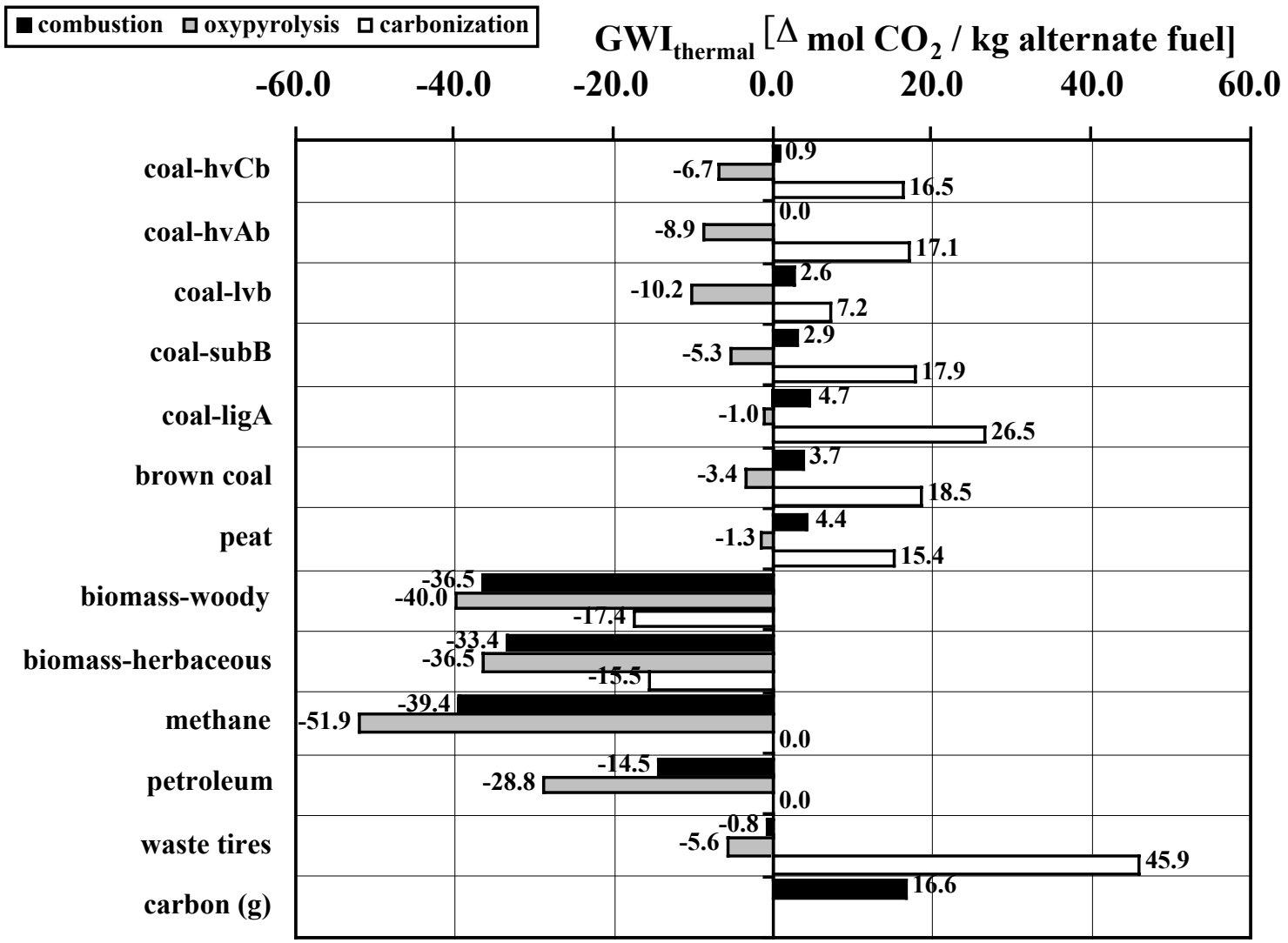

Figure 15: Global Warming Index values on a thermal basis for combustion, oxypyrolysis (ASTM), and carbonization (ASTM) of various fuels as an alternative to hvAb coal combustion, on a dry basis.

An interesting result here is that, though both not as favorable as biomass oxypyrolysis, biomass carbonization provides most of the emissions improvement that co-firing would. This realization could play an especially important role if investments in energy-use infrastructure, necessary for combustion and oxypyrolysis, are nearly prohibitory.

\section{Electricity Global Warming Index}

Finally, as the results associated with the biomass species are particularly important, these cases were examined in more detail. Specifically, to supplement the GWI results presented up to this 
point that assume that the end product of fuel processing is heat $\left(\mathrm{GWI}_{\text {thermal }}\right)$, biomass fuel scenarios where developed under the assumption that the end product is instead electricity $\left(\mathrm{GWI}_{\text {electric }}\right)$. Whereas for heat production, where it was assumed that the evolved energy is used for process heat (e.g. steam) with equal efficiency for all fuel and process combinations, appropriate efficiency values must be used for each alternate process when electricity is the end product. Stand-alone electricity production is investigated here, requiring equipment separate from that for the baseline condition, as opposed to co-firing for electricity, which requires no separate

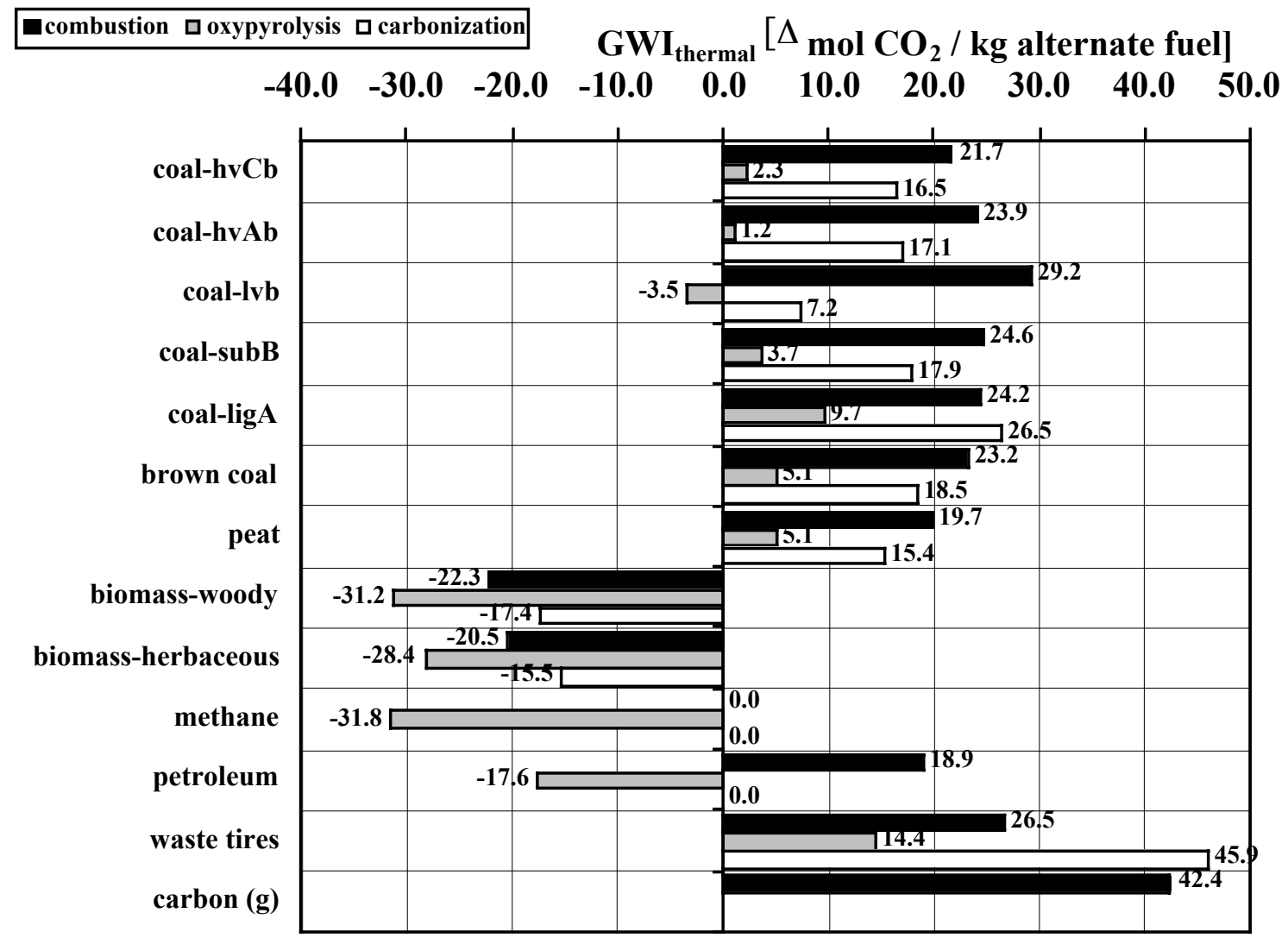

Figure 16: Global Warming Index values on a thermal basis for combustion, oxypyrolysis (ASTM), and carbonization (ASTM) of various fuels as an alternative to natural gas (methane) combustion, on a dry basis.

equipment for the alternative fuel conversion, and hence no separate efficiency value. Stand-alone electricity production by combustion and by gasification was explored.

The efficiency values for electricity production, $\eta$, account for the varying efficiencies of coal-fired, natural gas-fired, and biomass-fired power production equipment. The calculation of the $\mathrm{GWI}_{\text {electric, }}$, then, should reflect the effects of differing first-law efficiencies. Mathematically, GWI ${ }_{\text {electric }}$ calculation is identical to $\mathrm{GWI}_{\text {thermal }}$ calculation (Equation 21). For co-firing in coal-fired units, GWI calculations were not modified because co-firing efficiencies are similar to the efficiency of 
the baseline coal firing. Considering the stand-alone processes, modification is necessary. This modification is reflected through the switching ratio:

$$
G W I_{\text {thermal }}=(D C E \Delta h)-\left(D C E_{\text {baseline }} \Delta h \frac{\eta_{\text {alternative }}}{\eta_{\text {baseline }}}\right)-G D I,
$$

\section{First-Law Efficiency Values}

The $\eta$ values used for this study are typical for real processes, not the theoretical maximum efficiency, $\eta_{\max }$. Typical efficiencies for the following processes have been used in this consideration: $35 \%$ for coal combustion-to-electricity or for co-firing coal and biomass for electricity, $25 \%$ for stand-alone biomass combustion-to-electricity, $40 \%$ for wood gasification-toelectricity [Paisley, et al., 2001] and 55\% natural gas-to-electricity via a combined-cycle [Steinberg, 1999a].

\section{$G W I_{\text {electric }}$ Values}

Figures 17 and 18 reveal the results of these considerations for the coal and gas baselines, respectively, using the fixed carbon yields determined by ASTM proximate analysis.

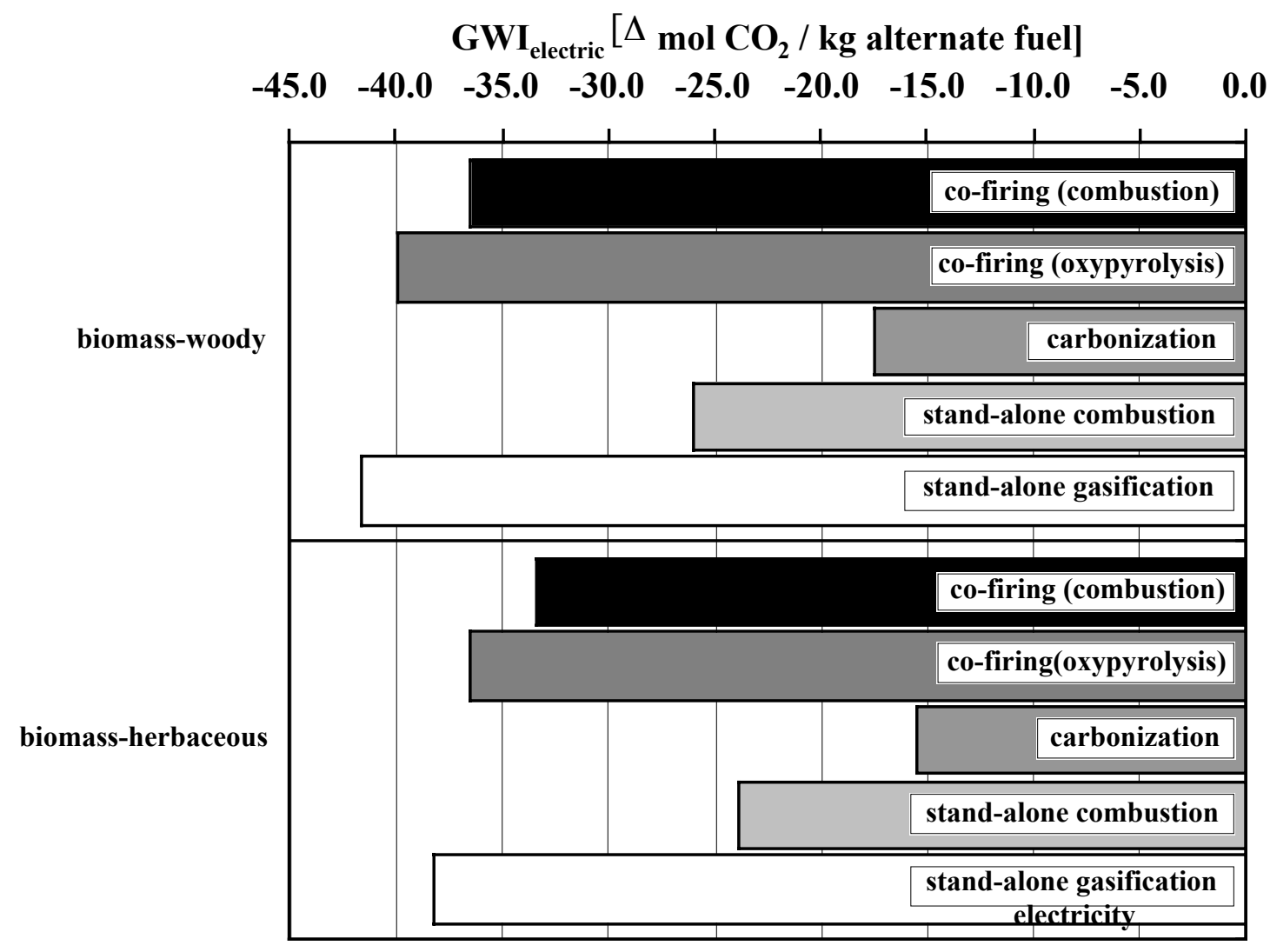

Figure 17: Biomass Global Warming Index values on an electricity basis for various processing methods as an alternative to hvAb coal combustion, on a dry basis. Oxypyrolysis and carbonization values assume fixed carbon yields as determined by ASTM proximate analysis. 


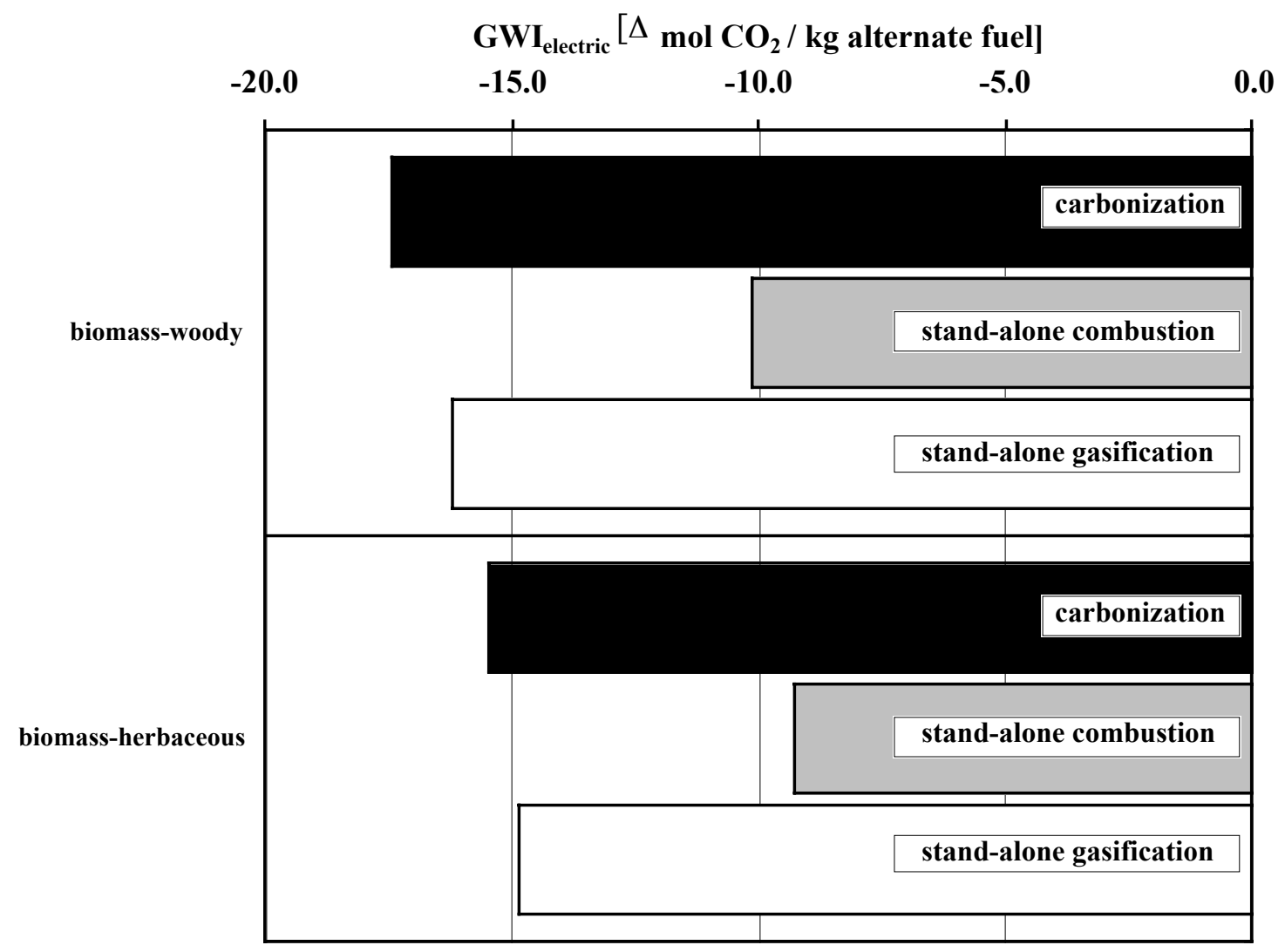

Figure 18: Biomass Global Warming Index values on an electricity basis for various processing methods as an alternative to natural gas (methane) combustion, on a dry basis. Carbonization values assume fixed carbon yields as determined by ASTM proximate analysis.

In a coal baseline environment, electricity-production considerations reinforce that carbonization is not easily justified as an alternative biomass processing method when equipment for energy extraction is available. Oxidative pyrolysis, is advantageous thermodynamically, but would require more extensive modification of existing units than co-firing, and would yield a high-carbon solid waste stream. Realistically, co-firing biomass is the most viable alternative to simple coal combustion, providing twice as much net $\mathrm{CO}_{2}$ reduction than carbonization. Processing biomass for electricity use using current technologies for stand-alone combustion is slightly more favorable than carbonization, but the added cost and complexity of the former would likely make the arrangement unwarranted. Generating electricity by gasification, however, can significantly benefit global warming. If the biomass fuel stream is produced near an existing biomass gasification plant, where transportation and other associated costs were minimal, the biomass should surely be used for energy production via that process, as suggested by this alternative's superior potential for reducing emissions.

When considering a natural gas baseline, the conclusions drawn about alternative methods for biomass waste use are entirely different, and thought-provoking. First, there is no realistic way to consider co-firing biomass in an existing natural gas combustion unit, as suggested by the absence of this option in Figure 18. The inability to process solid fuels with natural gas is not the only 
obstacle to biomass co-processing; the greater efficiency of the gas turbine combined cycle as compared to conventional solid fuel combustors and gasifiers makes it difficult to warrant alternatives to natural gas combustion. This realization is made clear by the large reduction in the emissions reduction benefit of stand-alone combustion or stand-alone gasification of biomass when considered as an alternative to natural gas combustion; the benefits are less than half of those associated with the replacement of high-volatile bituminous coal combustion. The reduced benefits of these stand-alone processes, however, now make simple carbonization of biomass an interesting alternative to natural gas combustion. Surprisingly, then, when electrical energy requirements are successfully met by natural gas combustion, the impact on global warming could be considerably reduced by simply charring the available biomass rather than using it for dedicated electricity production!

\section{CONCLUSIONS}

The findings of this study show that there are several ways to lessen the anthropogenic impact on atmospheric carbon dioxide levels using solid fuel technologies. The thermodynamically optimal way to process solid fuels depends on the specific fuels and technologies available, the demand for heat or for electricity, and the local baseline energy-production method. Burning renewable fuels reduces anthropogenic $\mathrm{CO}_{2}$ emissions as widely recognized. In certain cases, however, other processing methods are equally or more effective, including the simple carbonization or oxidative pyrolysis of biomass fuels.

Specifically, the thermodynamic analyses carried out here lead to the following conclusions:

1. Of all practical solid fuels, elemental carbon (char) produces the largest amount of carbon dioxide per unit heating value, and is the worst fuel for global warming concerns. As a result, partial combustion processes, or "oxypyrolysis" process, that leave part or all of the char unburned always produce lower $\mathrm{CO}_{2}$ emissions per unit heating value than conventional combustion.

2. Carbonization of biomass and other fast-decaying waste fuels can produce a significant reduction in net $\mathrm{CO} 2$ emissions evne without energy recovery . Waste fuel carbonization and elemental carbon storage may be the most viable global warming abatement technology in some locations in the developing world, and in some local settings in the developed world where natural gas is fired as a baseline fuel (see below).

3. The relative merits of combustion, oxidative pyrolysis, and carbonization depend strongly on the fuel type, the local heating/electricity needs, and the baseline fossil fuel in the region of interest. Specifically:

(a) in an environment with coal-based power generation, biomass cofiring is the most attractive practical utilization scheme for global warming abatement. Biomass carbonization offers about $50 \%$ of the benefit and has the added complexity of carbon storage. Oxidative pyrolysis is the most effective thermodynamically (as in all cases) but the additional $\mathrm{CO}_{2}$ reduction is only about $10 \%$ and would like not 
justify the additional complexity associated with power station retrofit and the storage of high-carbon waste streams.

(b) in an environment with natural-gas based power generation, cofiring is not possible and biomass fuels would need to be burned in dedicated units. These units have lower efficiencies and further are producing power that displaces methane, which itself has a lower emissions index than coal. As a result, the carbonization of biomass in this scenario offers almost twice the $\mathrm{CO}_{2}$ offset as conventional combustion and is slightly higher than gasification.

In general, biomass carbonization or oxypyrolysis with carbon storage may be an attractive option for global warming abatement at local sites where there is (1) little need for steam heat, and (2) there is no possibility for electricity generation, or where electricity is already generated by natural gas. For these particular cases the thermodynamic analyses carried out here should be extended to a detailed engineering and commercial analysis that considers optimal charring technologies, equipment selection, process economics, and issues of societal acceptance and the role in the overall world effort at global warming abatement.

\section{REFERENCES}

American Chemical Society, Pre-prints of symposia / Division of Fuel Chemistry 45 (4), 2000.

Antal, M.J., Croiset, E., Dai, X.F., DeAlmeida, C., Mok, W.S.L., Norberg, N., Richard, J.R., and AlMajthoub, M., “High-yield biomass charcoal,' Energy \& Fuels 10, p. 652-658, 1996.

Bilger, R.W., "Zero release combustion technologies and the oxygen economy," Fifth International Conference on Technologies and Combustion for a Clean Environment, Lisbon, Portugal, p.1039-1046, 1999.

Bilger, R.W., "On greenhouse constraints upon the combustion of fossil fuels," Australian meeting of the Combustion Conference, p. 207-211, 1999.

Bilger, R.W., "The future for energy from combustion of fossil fuels", Fifth International Conference on Technologies and Combustion for a Clean Environment, Lisbon, Portugal, p. 617$623,1999$.

Demirba_, A., "Properties of charcoal derived from hazelnut shell and the production of briquettes using pyrolytic oil," Energy 24, p.141-150, 1999.

Dionco-Adetayo, E.A., "Utilization of wood wastes in Nigeria: a feasibility overview," Technovation 21, p. 55-60, 2001.

Freeman, C., Evans, C.D., and Monteith, D.T., "Export of organic carbon from peat soils," Nature 412, p. 785, 2001.

Hallman, M.M. and Steinberg, M., Greenhouse Gas Carbon Dioxide Mitigation: Science and Technology, Lewis Publishers, New York, 1999. 
Intergovernmental Panel on Climate Change, Working Group 1, Climate Change 1995, Houghton, J.T. et al., Eds., Cambridge University Press, Cambridge, 1996.

Johansson, T.B., Williams, R.H., Ishitani, H., and Edmonds, J.A., "Options for reducing $\mathrm{CO}_{2}$ emissions from the energy supply sector,” Energy Policy 24, p. 985-1003, 1996.

Keeling, C.D. and Whorf, T.P., ORNL/CD/AC 65, Carbon Dioxide Information Analysis Center, Oak Ridge National Laboratory, Oak Ridge, TN 1995.

Kemkar, N., "The scrap tire problem in Rhode Island: analysis and recommendations," undergraduate thesis, Brown University Department of Environmental Studies, p.8, 2001.

Klass, D.L., Biomass for Renewable Energy, Fuels, and Chemicals, Academic Press, New York, 1998.

Kyle, B.G., Chemical and Process Thermodynamics, $3^{\text {rd }}$ Ed., Prentice Hall, Upper Saddle River, NJ, 1999.

Luoga, E.J., Witkowski, E.T.F., and Balkwill, K., "Economics of charcoal production in miombo woodlands of eastern Tanzania: some hidden costs associated with commercialization of the resources," Ecological Economics 35, p. 243-257, 2000.

Mori, Y., Masutani, S.M., Nihous, G.C., Vega, L.A., and Kinoshita, C.M., "Pre-combustion removal of carbon dioxide from hydrocarbon-fuelled power plants," Fuel 72, p.1293-1299, 1993.

National Research Council, "Carbon Dioxide and Climate: A Scientific Assessment," Report of an Ad Hoc Study Group on Carbon Dioxide and Climate (J.G. Charney, chairman), National Academy of Sciences, Washington, D.C., 1979.

Office of Science, Office of Fossil Energy, and United States Department of Energy, Carbon Sequestration and Development, available online at www.ornl.gov/carbon_sequestration/, 1999.

Okello, B.D., O’Connor, T.G., and Young, T.P., "Growth, biomass estimates, and charcoal production of Acacia drepanolobium in Laikipia, Kenya," Forest Ecology and Management 142, p.143-153, 2001.

Paisley, M.A., Irving, J.M., Overend, R.P., “A promising power option - the Ferco SilvaGas ${ }^{\mathrm{TM}}$ biomass gasification process - operating experience at the Burlington gasifier," Proceedings of the ASME Turbo Expo, New Orleans, June 2001.

Steinberg, M., "Efficient natural gas technologies: a response to global warming," Chemtech 29 (1), p. 31, 1999.

Steinberg, M., "Fossil fuel decarbonization technology for mitigating global warming," International Journal of Hydrogen Energy 24, p. 771-777, 1999.

Steinberg, M., "The Carnol process system for $\mathrm{CO}_{2}$ mitigation and methanol reduction," Energy $22(2 / 3)$, p.143-149, 1997. 
Steinberg, M., "The Carnol process for $\mathrm{CO}_{2}$ mitigation from power plants and the transportation sector," Energy Convers. Mgmt. 37 (6-8) , p.843-848, 1996.

Tillman, D.A., The Combustion of Solid Fuels and Wastes, Academic Press, New York, 1991.

Ward, D.E., Hao, W.M., and Babbitt, R.E., "Combustion Efficiency and hydrocarbon emissions from charcoal production kilns in the tropics," Abstracts of Papers of the American Chemical Society 209 (47-Cell, Part 1), 1995.

Wark, Jr., K., Thermodynamics, $5^{\text {th }}$ Ed., McGraw-Hill, New York, 1988.

Yokoyama, S.-Y., "Potential land area for reforestation and carbon dioxide mitigation effect through biomass energy conversion," Energy Convers. Mgmt. 38 (Suppl.), p. S569-S573, 1997.

Zabel, R.A., and Morrell, J.J., Wood Microbiology: Decay and Its Prevention, Academic Press, New York, 1997.

Zandersons, J., Gravitis, J., Kokorevics, A., Zhurinsh, A., Bikovens, O., Tardenaka, A., and Spince, B., "Studies of the Brazilian sugarcane bagasse carbonization process and products properties," Biomass and Bioenergy 17, p.209-219, 1999. 